\title{
Identification of new kinase clusters required for neurite outgrowth and retraction by a loss-of-function RNA interference screen
}

\author{
SHY Loh ${ }^{1}$, L Francescut ${ }^{1}$, P Lingor ${ }^{2,3}, M^{3}$ Bähr ${ }^{2,3}$ and P Nicotera*,1
}

Disruption of synaptic integrity, loss of connectivity and axodendritic degeneration are early and essential components of neurodegeneration. Although neuronal cell death mechanisms have been thoroughly investigated, less is known about the signals involved in axodendritic damage and the processes involved in regeneration. Here we conducted a genome-wide RNA interference-based forward genetic screen, using small interfering RNA targeting all human kinases, and identified clusters of kinases families essential for growth cone collapse, neurite retraction and neurite outgrowth. Of 59 kinases identified as positive regulators of neurite outgrowth, almost $50 \%$ were in the tyrosine kinase/tyrosine kinase-like (TK/TKL) receptor subgroups, underlining the importance of extracellular ligands in this process. Neurite outgrowth was inhibited by 66 other kinases, none of which were TK/TKL members, whereas 79 kinases inhibited lysophosphatidic acid-induced neurite retraction. Twenty kinases were involved in both inhibitory processes suggesting shared mechanisms. Within this group of 20 kinases, some (ULK1, PDK1, MAP4K4) have been implicated previously in axonal events, but others (MAST2, FASTK, CKM and DGUOK) have not. For a subset of kinases, the effect on neurite outgrowth was validated in rat primary cerebellar cultures. The ability to affect regeneration was further tested in a model of axodendritic lesion using primary rat midbrain cultures. Finally, we demonstrated that haploinsufficiency of two members of the AGC kinase subgroup, ROCK1 and PKN1, was able to suppress retinal degeneration in Drosophila model of class III Autosomal Dominant Retinitis Pigmentosa.

Cell Death and Differentiation (2008) 15, 283-298; doi:10.1038/sj.cdd.4402258; published online 16 November 2007

Neurodegenerative diseases, such as Alzheimer's, Parkinson's and Huntington's, are characterized by neuronal degeneration in the central nervous system (CNS). Research efforts have focused mainly on neuronal demise, of which apoptosis, necrosis and autophagic death of the neuronal soma are the most commonly described. ${ }^{1}$ On the contrary, the disruption of synaptic integrity, loss of connectivity and axonal degeneration which often precede, and are not always associated with, neuronal demise have not been thoroughly addressed. Although the mechanisms leading to axonal degeneration are largely unknown, there is compelling evidence that different execution systems operate in the axons and in the soma during neuronal degeneration. ${ }^{2-4}$ Selective, localized processes are also critical for neurite sprouting, axon growth, extension of the dendritic tree and establishment of precise connections with specific target cells. These are active during neuronal development, but they are also important for neuronal plasticity, as well as neuronal regeneration after damage to neurites and nerve endings.

Processes of both neuronal degeneration and regeneration involve complex signalling cascades leading to remodelling of cytoskeletal architecture, changes in ion signalling and mitochondrial function and distribution. Several signalling cascades involved in neurodegenerative/regenerative processes involve protein phosphorylation by kinases. 5,6 Aberrantly active protein kinases have been implicated in a variety of disease states, including neurodegenerative disorders ${ }^{7,8}$ and kinases are directly responsible for some of the most characteristic neuronal alterations in neurodegeneration. For example, CDK5 and GSK3 $\beta$ regulate hyperphosphorylation of the microtubule-associated protein tau and formation of intraneuronal neurofibrillary tangles (NFTs) in Alzheimer's disease (AD) patients. ${ }^{9,10}$ Overexpression of CDK5 and GSK3 $\beta$ in neuronal cultures and transgenic animal models not only leads to tau phosphorylation but also causes cytoskeletal structural abnormalities and neurodegeneration. ${ }^{11}$ Recent studies indicate that the genes encoding the PINK1 and LRRK2 protein kinases are mutated in patients with early and late onset Parkinson's disease, respectively ${ }^{12-16}$ and work in Drosophila melanogaster has provided further evidence of the role of mutant PINK1 in mitochondria dysfunction and cell death. ${ }^{17}$ Altered kinase activity is essential for the neurodegenerative effects of mutant PINK1 and LRRK2. Pathogenic mutants and kinase-dead PINK1 abrogate the neuroprotective effect of wild-type PINK1, ${ }^{18}$ whereas pathogenic mutations in LRRK2 increase its kinase

\footnotetext{
${ }^{1}$ MRC Toxicology Unit, University of Leicester, Leicester, UK; ${ }^{2}$ Department of Neurology, Georg-August-University Göttingen, Faculty of Medicine, Waldweg 33, Göttingen, Germany and ${ }^{3}$ DFG-Research Center for Molecular Physiology of the Brain (CMPB), Göttingen, Germany

*Corresponding author: P Nicotera, MRC Toxicology Unit, Hodgkin Building, Lancaster Road, Leicester, LE1 9HN, UK. Tel: + 44 1162525611; Fax: + 44 1162525599; E-mail: pn10@le.ac.uk

Keywords: RNAi screen; human kinases; neurite outgrowth; neurite retraction

Abbreviations: AD, Alzheimer's disease; CNS, central nervous system; CGN, cerebellar granule neurons; DIV, days in vitro; db-cAMP, dibutyryl-cyclic AMP; EGFP, enhanced green fluorescent protein; GFP, green fluorescent protein; LPA, lysophosphatidic acid; mtDNA, mitochondrial DNA; PKA, protein kinase A; PKG, protein kinase G; PKC, protein kinase C; RNAi, RNA interference; siRNA, small interfering RNA; TK/TKL, tyrosine kinase/tyrosine kinase-like

Received 23.7.07; revised 21.9.07; accepted 24.9.07; Edited by G Melino; published online 16.11.07
} 
activity, and cause neurodegeneration in neuronal cultures. ${ }^{19-22}$ Several other kinases, such as members of the casein kinases family (CK $1 \delta, \mathrm{CK} 1 \alpha)$ and DYRK $1 \mathrm{~A}$, have also been implicated in tauopathies such as $A D$, based on their abilities to phosphorylate tau, as well as $\beta$-secretase and presenilin, two other proteins linked to AD. ${ }^{23,24}$

Despite the enormous research focus on individual pathways involving kinase regulation in neurodegenerative disorders, the underlying consequences of a disturbed signalling machinery are still obscure. Most importantly, although the position of individual kinases in signal transduction is well established in many cases, there is no comprehensive picture of the overall cross-talk between kinase families in pathophysiological processes. To address this complexity, we designed an RNA interference (RNAi)-based forward genetic screen, using small interfering RNA (siRNA) targeting the majority of human kinases, with the aim of identifying clusters of kinases essential for growth cone collapse, neurite retraction and neurite outgrowth. In addition to unraveling the complex interactions between different kinase families, this study has also uncovered novel roles for kinases that have not yet been assigned a function or have not previously been implicated in neuronal function. This may foster new understanding of mechanisms involved in neurodegeneration and help in designing effective and non-toxic treatments based on modulation of different kinase subsets.

\section{Results}

High-throughput screen of human kinases involved in neurite outgrowth. To establish the role of protein kinases in neurite outgrowth and retraction, we designed a functional assay using the human neuroblastoma cell line, SH-SY5Y. In the presence of dibutyryl-cyclic AMP (db-cAMP), SHSY5Y cells form elongated $\beta$-III tubulin-immunopositive processes within $48 \mathrm{~h}$ (Figure $1 \mathrm{a}$ and $\mathrm{b}$ ). The average neurite length per neuron (ANL/neuron) for nondifferentiated and differentiated cells was 40-50 and 70$80 \mu \mathrm{m}$, respectively (Figure 1e). SH-SY5Y cells were then systematically transfected with siRNAs using a kinome library comprising 750 kinases at three-fold redundancy. Cells were then differentiated in medium containing db-cAMP (Supplementary Figure 1). Under these conditions, more than $92 \%$ of cells were transfected with siRNA (Supplementary Figure 2). As selection criterion, we used neurite length and considered a kinase to be genuine when two or more siRNA against the same candidate kinase produced the same phenotype (low or high ANL/neuron). Because undifferentiated SH-SY5Y cells undergo cell division, siRNAs to some kinases also affected their proliferation rate and thereby might have affected only indirectly their neurite outgrowth (Figure 1g). However, some cell cycle kinases were also involved in neurite outgrowth suggesting possible new functions for this kinase family. After two rounds of stringent analyses, siRNAs (two or more) that increase the ANL/neuron to $>100 \mu \mathrm{m}$ were defined as promoting neurite outgrowth and those that decrease the $\mathrm{ANL} /$ neuron to $<70 \mu \mathrm{m}$ were defined as inhibiting neurite outgrowth (Figure 1f).
High-throughput screen of human kinases involved in neurite retraction. In the neurite retraction assay, db-cAMPdifferentiated cells were treated with lysophosphatidic acid (LPA) for $1 \mathrm{~h}$ to induce growth cone collapse and neurite retraction (Figure $2 \mathrm{~b}$ ). As a positive control, we used siRNA to Rock1, which is known to inhibit these processes (Katoh et al. $^{25}$ and Figure 2c). In addition, LPA induction also caused the cell body to flatten (Figure $2 b$ and $c$ ). In this screen, the ANL/neurite for differentiated cells with or without LPA induction was 10.18 and $13.58 \mu \mathrm{m}$, respectively (Figure $2 \mathrm{~g}$ ). As for the outgrowth screen, the entire retraction screen was repeated and an average of both experiments were analysed. siRNAs (two or more) that maintained ANL/neurite to $>12 \mu \mathrm{m}$ were defined as inhibiting LPA-induced neurite retraction (Figure 2h).

Analysis of the screen data. Our analysis revealed that siRNA-targeted downregulation of $\sim 8 \%$ (59 candidates) of the kinome library resulted in neuronal cells exhibiting short neurite length (Table 1). In the case of 13 kinases, neurite outgrowth was inhibited by all three independent siRNAs. The efficiency of downregulation by all three siRNAs for four candidates (SNARK1, EPHA1, ERBB2 and JAK1) was further confirmed by quantitative RT-PCR (Supplementary Figure 3 ). Interestingly, inhibition of neurite outgrowth by LIMK1 was observed from only two independent siRNAs and this was due to an inefficient downregulation by the third siRNA (Supplementary Figure 3). Targeted downregulation of another $9 \%(66)$ kinases resulted in cells with abnormally long neurite length (Table 2). In the case of 15 kinases, neurite outgrowth was promoted by all three independent siRNAs.

The processes of growth cone collapse and neurite retraction induced by LPA were inhibited by 79 kinases. Interestingly, 20 of these kinases were identical to those which inhibited neurite outgrowth (Table 3 and Figure 3), suggesting a shared mechanism in the inhibition of outgrowth and retraction. The kinases identified in all three data sets are clustered in the kinome (http://kinase.com). The majority $(50 \%)$ of the positive modulators of neurite outgrowth (inhibitory candidates) belong to the tyrosine kinase (TK) and tyrosine kinase-like (TKL) subgroups (Table 1 and Figure 3 ). This finding suggests that neurite outgrowth is promoted primarily by extracellular ligands and growth factors and suggests that this subset of kinases could be a potential target for therapeutic intervention. However, on the contrary, most of the negative modulators (stimulatory candidates) of neurite outgrowth are from the AGC (containing protein kinase A (PKA), protein kinase $G(P K G)$, protein kinase $C$ (PKC) families) subgroup and no TK/TKL kinases are involved in this process (Table 2 and Figure 3). Promotion and inhibition of neurite outgrowth required signalling from different subgroups of kinase families. Our results also revealed that the control of neurite length required a balance of cellular signals that both promotes and restricts neurite outgrowth. By contrast, no kinases that promote neurite outgrowth were involved in LPAinduced neurite retraction. The $27 \mathrm{TK} / \mathrm{TKL}$-positive modulators of neurite outgrowth were different from the $19 \mathrm{TK} / \mathrm{TKL}$ kinases involved in the retraction, suggesting that distinct and 

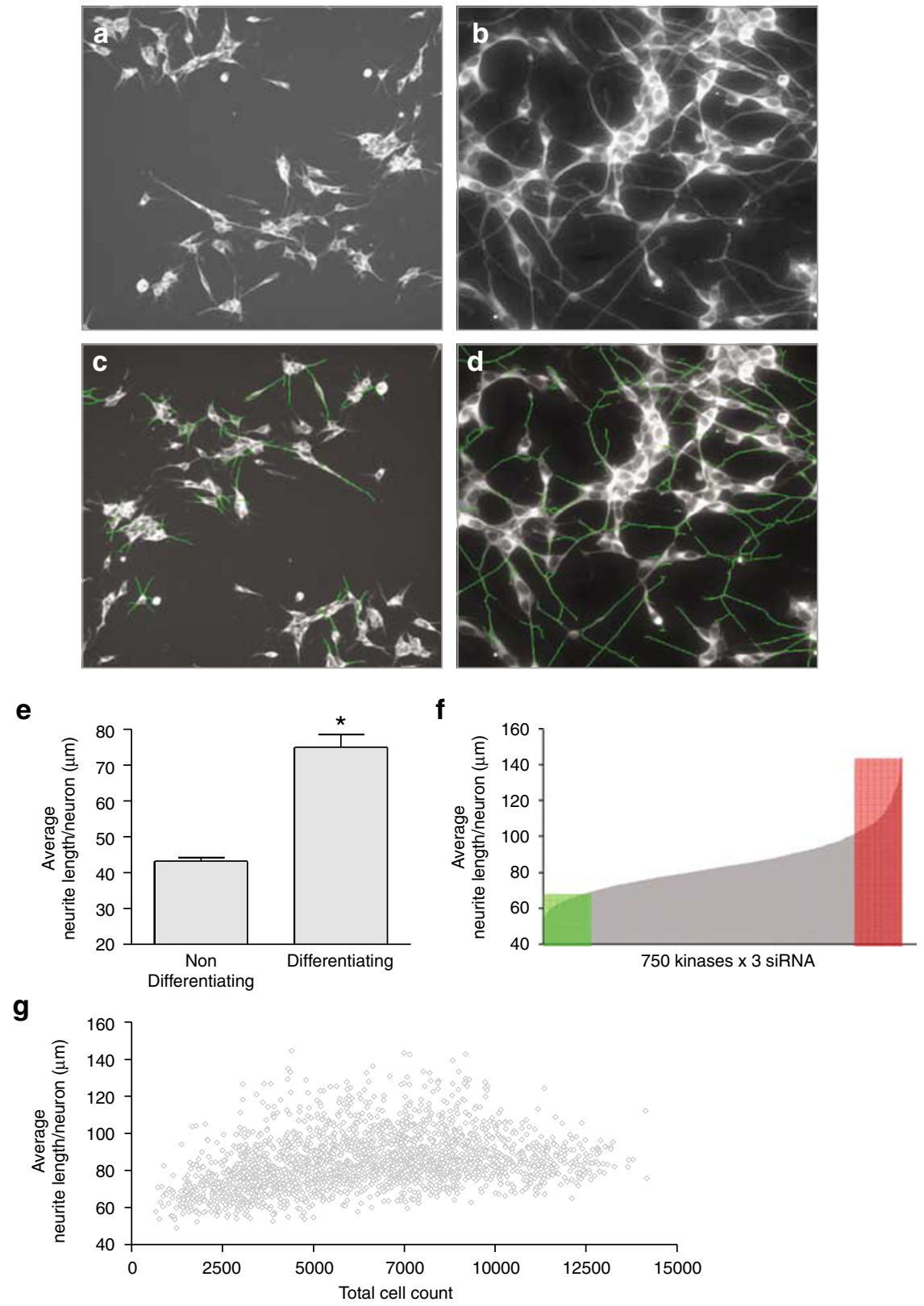

Figure 1 The high throughput neurite outgrowth assay. SH SY-5Y cells were fixed after $48 \mathrm{~h}$ in non-differentiating (a and $\mathbf{c})$ or differentiating (b and $\mathbf{d})$ medium and immunostained with neuronal-specific marker $\beta$ III tubulin. Fluorescence images (with $10 \times$ magnification) acquired using the Cellomics High Content system (a and $\mathbf{b}$ ) and the same images following application of neurite outgrowth algorithm (c and d). (e) A histogram showing the average neurite length/neuron of SH SY-5Y cells in differentiating or non-differentiating medium $48 \mathrm{~h}$ post-transfection with scrambled siRNA. Error bars $=$ S.D., $n=40$ in all groups, ${ }^{*} P$ value $=1.98 \times 10^{-35}$ with one tailed $t$-test. (f) A histogram showing the average neurite length/neuron of all samples (750 kinases siRNA with three-fold redundancy). Candidates with average neurite length/neuron less than $70 \mu \mathrm{m}$ and more than $100 \mu \mathrm{m}$ were highlighted in green and red, respectively. (g) A scatter plot showing the distribution of total numbers of neuron acquired and their respective calculated average neurite length per neuron

non-over-lapping signalling mechanisms are responsible for these two processes.

Validation of the screens in primary neurons. To validate the authenticity of our screen results, we selected a subset of siRNA to downregulate kinases in primary cultures of cerebellar granule neurons (CGN). Two independent siRNAs to rat orthologues of six candidates (cdc2a, ulk1, mast2, fastk, pdk1 and map4k4), identified by the promoting outgrowth data set, were co-transfected with a green fluorescent protein (GFP) reporter construct and fluorescence images of siRNA-transfected cultures were acquired 2 days post-transfection (Figure $4 a-d$ ). The outgrowth of neuronal processes from GFP-positive neurons was quantified and compared to cultures transfected with scrambled siRNA. The neurite length/ neuron values were significantly higher than those with scrambled siRNA control for all CGN cultures (Figure 4). 

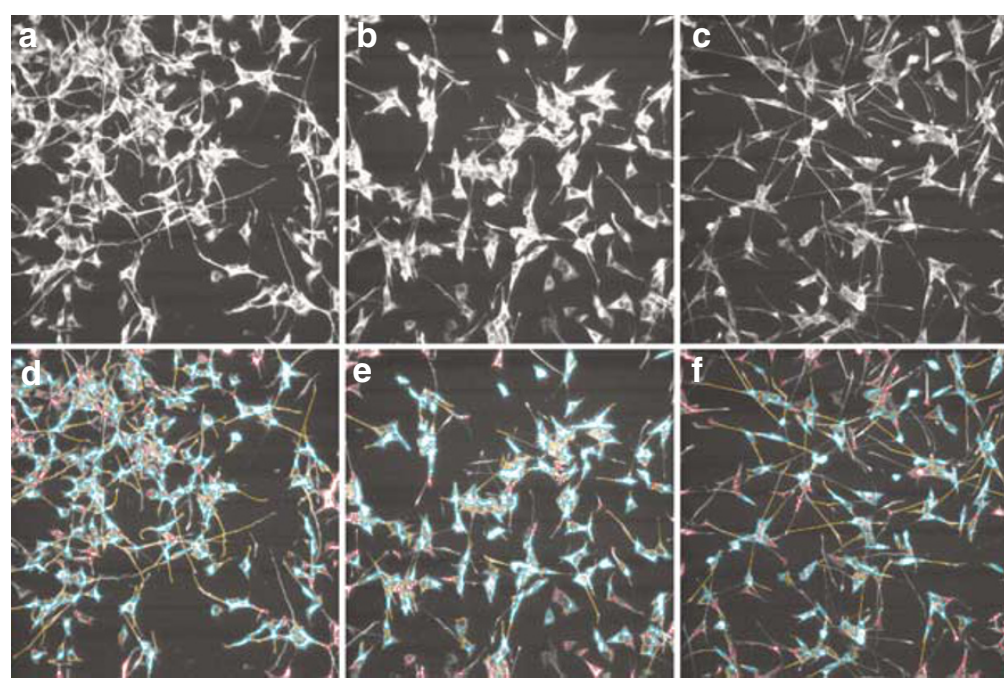

g

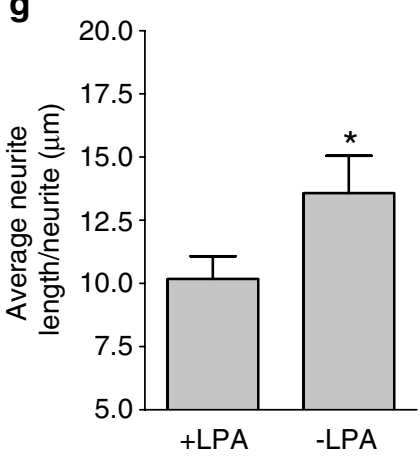

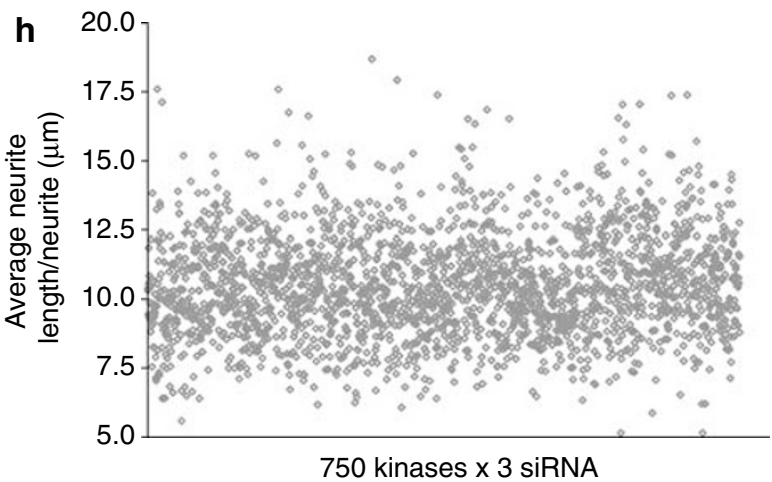

750 kinases $\times 3$ siRNA

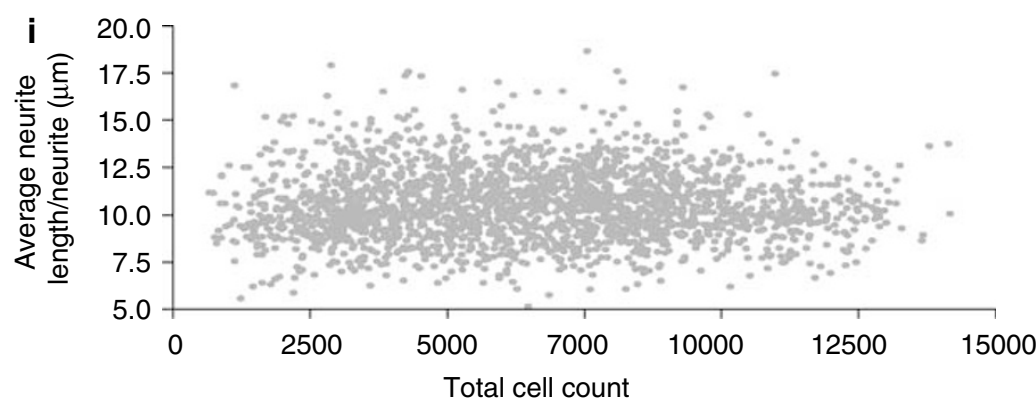

Figure 2 The high throughput neurite retraction assay. SH SY-5Y cells were fixed $48 \mathrm{~h}$ post-transfection with scrambled siRNA (a, b, $\mathbf{d}$ and $\mathbf{e})$ or ROCK1 siRNA (c and $\mathbf{f})$ in differentiating medium and immunostained with neuronal-specific marker $\beta$ III tubulin. Fluorescence images (with $\times 10$ magnification) acquired using the Cellomics High Content system (a, $\mathbf{b}$ and $\mathbf{c}$ ) and the same images following application of extended neurite Outgrowth algorithm (d, e and $\mathbf{f})$. (g) A histogram showing the average neurite length/neurite of SH SY-5Y cells in differentiating medium, with or without $10 \mu \mathrm{M} \mathrm{LPA}$ induction, $48 \mathrm{~h}$ post-transfection with scrambled siRNA. Error bars $=$ S.D., $n=104$ in all groups, ${ }^{*} P$ value $=9.0 \times 10^{-42}$ with one tailed $t$-test. (h) A histogram showing the average neurite length/neurite of all samples $(750$ kinases siRNA with three-fold redundancy). Candidates with average neurite length/neurite more than $12 \mu \mathrm{m}$ were defined as inhibiting LPA-induced neurite retraction. (i) A scatter plot showing the distribution of total numbers of neuron acquired and their respective calculated average neurite length per neurite

The regeneration data were validated in another subset of kinases using a model of primary dopaminergic neuron regeneration. ${ }^{26}$ Axons were transected at day in vitro (DIV) 3 and siRNA-transfected cultures were then kept until DIV 6 to allow for regeneration of lesioned axons. Regeneration from the edge of the transection was then quantified and compared to cultures transfected with a control-siRNAtargeting enhanced green fluorescent protein (EGFP), where the length of regenerating neurites was set to $100 \%$
(Figure 5b). Regeneration in the overall culture, containing a majority of GABAergic cells and up to $10 \%$ dopaminergic neurons, was quantified in phase contrast images. A significant increase in the length of regenerating neurites was observed in cultures treated with siRNAs directed against CKM, FASTK, MAP4K4, ULK1, MAST2 and PDK1 (Figure 5a). The most pronounced effect on neurite regeneration was observed after knockdown of ULK1 $(167 \pm 12 \%)$, PDK1 $(165 \pm 15 \%)$ and FASTK $(163 \pm 19 \%)$ 
Table 1 RNAi knockdown inhibits neurite outgrowth

\begin{tabular}{|c|c|c|c|c|c|}
\hline $\begin{array}{l}\text { Amblon } \\
\text { name }\end{array}$ & $\begin{array}{l}\text { Also } \\
\text { known as }\end{array}$ & Full name & $\begin{array}{l}\text { Kinase } \\
\text { subgroup }\end{array}$ & $\begin{array}{c}\text { ANL/ } \\
\text { neuron }\end{array}$ & RefSeq Ace \\
\hline CHEK1 & & CHK1 checkpoint homolog (S. pombe) & CAMK & 66.82 & NM 001274 \\
\hline MARK3 & & $\mathrm{MAP} / \mathrm{microtubule}$ affinity-regulating kinase 3 & CAMK & 69.19 & NM_002376 \\
\hline MGC8407 & VACAMKL & & CAMK & 64.9 & NM_024046 \\
\hline SNARK & NuaK2 & & CAMK & 66.76 & NM_030952 \\
\hline TRAD & Kalirin & RhoGEF kinase & CAMK & 66.67 & NM_007064 \\
\hline TRIO & & Triple functional domain (PTPRF interacting) & CAMK & 69.72 & NM_007118 \\
\hline $\mathrm{CDK} 11$ & & cyclin-dependent kinase (CDC2-like) 11 & CMGC & 66.35 & NM_015076 \\
\hline CDK9 & & cyclin-dependent kinase 9 (CDC2-related kinase) & CMGC & 63.85 & NM_001261 \\
\hline CLK4 & & CDC-like kinase 4 & CMGC & 62.99 & NM_020666 \\
\hline PCTK3 & PCTAIRE3 & PCTAIRE protein kinase 3 & CMGC & 59.67 & $\begin{array}{l}\text { NM_002596, } \\
\text { NM_212502, } \\
\text { NM_212503 }\end{array}$ \\
\hline ALS2CR2 & STLK6 & amyotrophic lateral sclerosis 2 (juvenile) chromosome region, candidate 2 & STE & 66.64 & NM_018571 \\
\hline FLJ23074 & YSK4 & yeast Sps1/ste20-related kinase 4 & STE & 68.02 & NM_025052 \\
\hline LYK5 & STLK5 & & STE & 59.89 & $\begin{array}{l}\text { NM_001003786. } \\
\text { NM_001003787. } \\
\text { NM_001003788. } \\
\text { NM_153335 }\end{array}$ \\
\hline MAP2K6 & & mitogen-activated protein kinase kinase 6 & STE & 61.81 & $\begin{array}{l}\text { NM_002758. } \\
\text { NM_031988 }\end{array}$ \\
\hline MAP2K7 & & mitogen-activated protein kinase kinase 7 & STE & 64.89 & $\begin{array}{l}\text { NM_005043, } \\
\text { NM_145185 }\end{array}$ \\
\hline MAP3K4 & & mitogen-activated protein kinase kinase kinase 4 & STE & 64.29 & $\begin{array}{l}\text { NM_005922, } \\
\text { NM_006724 }\end{array}$ \\
\hline MAP3К8 & COT/TPL2 & mitogen-activated protein kinase kinase kinase 8 & STE & 62.62 & NM_005204 \\
\hline MAP4K5 & KHS1 & mitogen-activated protein kinase kinase kinase kinase 5 & STE & 64.22 & $\begin{array}{l}\text { NM_006575. } \\
\text { NM_198794 }\end{array}$ \\
\hline MINK & & & STE & 62.57 & $\begin{array}{l}\text { NM_015716, } \\
\text { NM_1 }^{-153827} \\
\mathrm{NM}^{-170663}\end{array}$ \\
\hline OSR1 & & oxidative-stress responsive 1 & STE & 66.2 & NM_005109 \\
\hline PAK1 & & p21/Cdc42/Rac1-activated kinase 1 (STE20 homolog, yeast) & STE & 66.49 & NM_002576 \\
\hline ALK & & anaplastic lymphoma kinase $(\mathrm{Ki}-1)$ & TK & 62.03 & NM_004304 \\
\hline $\mathrm{AXL}$ & & AXL receptor tyrosine kinase & TK & 68.19 & $\begin{array}{l}\text { NM_001699, } \\
\text { NM_021913 }\end{array}$ \\
\hline EPHA1 & & EphA1 & TK & 64.93 & NM_005232 \\
\hline EPHA2 & & EphA2 & TK & 66.98 & NM_004431 \\
\hline EPHA3 & & EphA3 & TK & 63.09 & $\begin{array}{l}\text { NM_005233, } \\
\text { NM } 182644\end{array}$ \\
\hline ERBB2 & & $\begin{array}{l}\text { v-erb-b2 erythroblastic leukemia viral oncogene homolog } 2 \text {, neuro/ } \\
\text { glioblastoma derived oncogene homolog (avian) }\end{array}$ & TK & 63.21 & NM_004448 \\
\hline FES & & feline sarcoma oncogene & TK & 64.86 & NM_002005 \\
\hline FGR & & Gardner-Rasheed feline sarcoma viral (v-fgr) oncogene homolog & TK & 65.32 & NM_005248 \\
\hline FLT3 & & fms-related tyrosine kinase 3 & TK & 54.55 & NM_004119 \\
\hline FLT4 & & fms-related tyrosine kinase 4 & TK & 56.31 & $\begin{array}{l}\text { NM_002020, } \\
\text { NM_182925 }\end{array}$ \\
\hline JAK1 & & Janus kinase 1 (a protein tyrosine kinase) & TK & 62.17 & NM_002227 \\
\hline JAK2 & & Janus kinase 2 (a protein tyrosine kinase) & TK & 65.23 & NM_004972 \\
\hline NTRK2 & TRKB & neurotrophic tyrosine kinase, receptor, type 2 & TK & 61.08 & NM_006180 \\
\hline RET & & $\begin{array}{l}\text { ret proto-oncogene (multiple endocrine neoplasia and medullary thyroid } \\
\text { carcinoma 1, Hirschsprung disease) }\end{array}$ & TK & 58.76 & $\begin{array}{l}\text { NM_000323, } \\
\text { NM_020629, } \\
\text { NM_020630, } \\
\text { NM_020975 }\end{array}$ \\
\hline ROR1 & & receptor tyrosine kinase-like orphan receptor 1 & TK & 66.96 & NM_005012 \\
\hline RYK & & RYK receptor-like tyrosine kinase & TK & 59.34 & NM_002958 \\
\hline STYK1 & SURTK106 & & TK & 63.24 & NM_018423 \\
\hline ACVR1C & ALK7 & activin $A$ receptor, type IC & TKL & 65.44 & NM_145259 \\
\hline ACVR2 & ACTR2 & activin $A$ receptor, type II & TKL & 68.29 & NM_001616 \\
\hline ACVR2B & ACTR2B & activin A receptor, type IIB & TKL & 63.32 & NM_001106 \\
\hline ACVRL1 & ALK1 & activin A receptor type II-like 1 & TKL & 61.16 & NM_000020 \\
\hline ANKK1 & Sgk288 & ankyrin repeat and kinase domain containing 1 & TKL & 65.86 & NM_178510 \\
\hline BRAF & B-RAF & v-raf murine sarcoma viral oncogene homolog B1 & TKL & 66.95 & NM_004333 \\
\hline FLJ34389 & MLKL & & TKL & 61.25 & NM 152649 \\
\hline LIMK1 & & LIM domain kinase 1 & TKL & 66.8 & $\begin{array}{l}\text { NM_002314, } \\
\text { NM_016735 }\end{array}$ \\
\hline MAP3K10 & MLK4 & mitogen-activated protein kinase kinase kinase 10 & TKL & 65.68 & NM 002446 \\
\hline TGFBR2 & & transforming growth factor, beta receptor II (70/80 kDa) & TKL & 62.22 & NM_003242 \\
\hline GCKR & & mitogen-activated protein kinase kinase kinase 10 & & 67.11 & NM_001486 \\
\hline LIM & & PDZ and LIM domains & & 63.58 & NM_006457 \\
\hline MAP3K7IP2 & & mitogen-activated protein kinase kinase kinase 7 interacting protein 2 & & 66.4 & $\begin{array}{l}\text { NM_015093, } \\
\text { NM_145342 }\end{array}$ \\
\hline MFHAS1 & & malignant fibrous histiocytoma amplified sequence 1 & & 59.95 & NM_004225 \\
\hline
\end{tabular}


Table 1 (Continued)

\begin{tabular}{|c|c|c|c|c|c|}
\hline $\begin{array}{l}\text { Amblon } \\
\text { name }\end{array}$ & $\begin{array}{l}\text { Also } \\
\text { known as }\end{array}$ & Full name & $\begin{array}{l}\text { Kinase } \\
\text { subgroup }\end{array}$ & $\begin{array}{c}\text { ANL/ } \\
\text { neuron }\end{array}$ & RefSeq Ace \\
\hline PIK3AP1 & & phosphoinositide-3-kinase adaptor protein 1 & & 67.84 & NM_152309 \\
\hline PIK3CD & & phosphoinositide-3-kinase, catalytic, delta polypeptide & & 63.67 & NM_005026 \\
\hline PIK3CG & & phosphoinositide-3-kinase, catalytic, gamma polypeptide & & 66.44 & NM_002649 \\
\hline P1K3R2 & & phosphoinositide-3-kinase, regulatory subunit, polypeptide 2 ( $p 85$ beta) & & 58.94 & NM_005027 \\
\hline PRKAB2 & & protein kinase, AMP-activated. beta 2 non-catalytic subunit & & 68.89 & NM_005399 \\
\hline PRKAR1B & & protein kinase, cAMP-dependent, regulatory, type I, beta & & 68.33 & NM_002735 \\
\hline SCAP1 & & src family associated phosphoprotein 1 & & 68.33 & NM_003726 \\
\hline
\end{tabular}

CAMK, calcium/calmodulin-dependent protein kinase; STE, homologs of yeast sterile 7, sterile 11, sterile 20 kinases; TK, tyrosine kinase; TKL, tyrosine kinase-like. The table shows 59 protein kinases with RNAi phenotype of inhibiting neurite outgrowth in our assay condition. These candidates were grouped according to the subgroup classification in the KINOME (http://kinase.com/human/kinome/). ${ }^{43} \mathrm{ANL} /$ neuron (average neurite length per neuron) represents average neurite length by three (underlined candidates) or two (un-underlined candidates) independent siRNAs calculated from two rounds of screens

Table 2 RNAi knockdown promotes neurite outgrowth

\begin{tabular}{|c|c|c|c|c|c|}
\hline $\begin{array}{l}\text { Ambion } \\
\text { name }\end{array}$ & $\begin{array}{l}\text { Also } \\
\text { known as }\end{array}$ & Full name & $\begin{array}{l}\text { Kinase } \\
\text { subgroup }\end{array}$ & $\begin{array}{c}\text { ANL/ } \\
\text { neuron }\end{array}$ & RefSeq Ace \\
\hline MAST2 & & microtubule associated serine/threonine kinase 2 & AGC & 100.19 & NM_015112 \\
\hline MASTL & & microtubule associated serine/threonine kinase-like & AGC & 103.76 & NM_032844 \\
\hline PDPK1 & & 3-phosphoinositide dependent protein kinase-1 & AGC & 102.92 & $\begin{array}{l}\text { NM } 002613 \\
\text { NM_031268 }\end{array}$ \\
\hline PRKCB1 & PKC beta & protein kinase C. beta 1 & AGC & 115.98 & $\begin{array}{l}\text { NM_002738, } \\
\text { NM_212535 }\end{array}$ \\
\hline ROCK1 & & Rho-associated, coiled-coil containing protein kinase 1 & AGC & 117.25 & NM_005406 \\
\hline ROCK2 & & Rho-associated, coiled-coil containing protein kinase 2 & AGC & 100.57 & NM_004850 \\
\hline RPS6KA4 & MSK2 & ribosomal protein S6 kinase, $90 \mathrm{kDa}$, polypeptide 4 & AGC & 107.56 & NM_003942 \\
\hline ADCK2 & & aarF domain containing kinase 2 & ATYPICAL & 107.75 & NM 052853 \\
\hline AOCK4 & & aarF domain containing kinase 4 & ATYPICAL & 159.08 & NM_024876 \\
\hline ATR & FRP-1 & ataxia telangiectasia and Rad3 related & ATYPICAL & 108.09 & NM_001184 \\
\hline BCKDK & & branched chain ketoacid dehydrogenase kinase & ATYPICAL & 106.09 & NM_005881 \\
\hline BCR & $\begin{array}{l}\text { PHL. } \\
\text { D22S662. } \\
\text { D22S11.CML. } \\
\text { BCR1, ALL }\end{array}$ & breakpoint cluster region & ATYPICAL & 109.59 & NM_004327, \\
\hline$\underline{B R D 3}$ & & bromodomain containing 3 & ATYPICAL & 104.05 & NM_007371 \\
\hline$\overline{\mathrm{BRDT}}$ & & bromodomain. testis-specific & ATYPICAL & 114.25 & $\begin{array}{l}\text { NM_001726, } \\
\text { NM_207189 }\end{array}$ \\
\hline $\mathrm{CABC} 1$ & $\begin{array}{l}\text { ADCK3, } \\
\text { LOC56997 }\end{array}$ & chapetone. $\mathrm{ABC} 1$ activity of bc1 complex like (S. pombe) & ATYPICAL & 118.98 & NM 020247 \\
\hline FASTK & $\begin{array}{l}\text { FAST. } \\
\text { FLJ13079 }\end{array}$ & & ATYPICAL & 112.02 & $\begin{array}{l}\text { NM_006712, } \\
\text { NM_025096 }\end{array}$ \\
\hline MIDORI & $\begin{array}{l}\text { ALPK3. } \\
\text { AlphaK3 }\end{array}$ & & ATYPICAL & 117.84 & NM_020778 \\
\hline$\underline{\text { SMG1 }}$ & & Pl-3-kinase-related kinase SMG-1 & ATYPICAL & 104.14 & $\begin{array}{l}\text { NM_014006, } \\
\text { NM_015092 }\end{array}$ \\
\hline TAF1 & & $\begin{array}{l}\text { TAF1 RNA polymerase II, TATA box binding protein } \\
\text { (TBP)-associated factor. } 250 \mathrm{kDa}\end{array}$ & ATYPICAL & 107.91 & $\begin{array}{l}\text { NM_004606, } \\
\text { NM_138923 }\end{array}$ \\
\hline TAF1L & & $\begin{array}{l}\text { TAF1-like RNA polymerase II, TATA box binding protein } \\
\text { (TBP)-associated factor, } 210 \mathrm{kDa}\end{array}$ & ATYPICAL & 128.93 & NM_153809 \\
\hline $\begin{array}{l}\text { TRPM6 } \\
\text { CDC2 }\end{array}$ & $\begin{array}{l}\text { CHAK2 } \\
\text { CDK1. } \\
\text { p34cdc2 }\end{array}$ & $\begin{array}{l}\text { transient receptor potential cation channel, subfamily } M \text {, member } 6 \\
\text { cell division cycle } 2, \mathrm{G} 1 \text { to } \mathrm{S} \text { and } \mathrm{G} 2 \text { to } \mathrm{M}\end{array}$ & $\begin{array}{l}\text { ATYPICAL } \\
\text { CMGC }\end{array}$ & $\begin{array}{l}125.54 \\
118.83\end{array}$ & $\begin{array}{l}\text { NM_017662 } \\
\text { NM_001786, } \\
\text { NM_033379 }\end{array}$ \\
\hline AURKC & $\begin{array}{l}\text { AURC, ALK3. } \\
\text { AIE2. STK13 }\end{array}$ & aurora kinase $\mathrm{C}$ & OTHER & 103.1 & NM_003160 \\
\hline BUB1 & & BUB1 budding uninhibited by benzImidazoles 1 homolog (yeast) & OTHER & 105.73 & NM_004336 \\
\hline CHUK & IKK alpha & conserved helix-loop-helix ubiquitous kinase & OTHER & 99.44 & NM_001278 \\
\hline CSNK2A2 & ck2alpha2 & casein kinase 2 . alpha prime polypeptide & OTHER & 115.26 & NM_001896 \\
\hline ERN2 & IRE2 & ER to nucleus signalling 2 & OTHER & 113.71 & NM_033266 \\
\hline FLJ32685 & NEK10 & & OTHER & 140.36 & $\mathrm{NM}^{-} 152534$ \\
\hline$\frac{\mathrm{HRI}}{\mathrm{MOS}}$ & & Y-mec Moloney murine sarcoma viral oncogene homolog & & 113.38 & NM_014413 \\
\hline $\begin{array}{l}\text { MOS } \\
\text { NEK11 }\end{array}$ & c-mos, msv & $\begin{array}{l}\text { V-mos Moloney murine sarcoma viral oncogene homolog } \\
\text { NIMA (never in mitosis gene a)-related kinase } 11\end{array}$ & $\begin{array}{l}\text { OTHER } \\
\text { OTHER }\end{array}$ & $\begin{array}{l}101.93 \\
110.07\end{array}$ & $\begin{array}{l}\text { NM_005372 } \\
\text { NM_024800, } \\
\text { NM_145910 }\end{array}$ \\
\hline NEK3 & & NIMA (never in mitosis gene a)-related kinase 3 & OTHER & 104.06 & $\begin{array}{l}\text { NM } 002498, \\
\text { NM_152720 }\end{array}$ \\
\hline NEK4 & & NIMA (never in mitosis gene a)-related kinase 4 & OTHER & 109.85 & NM_003157 \\
\hline NEK6 & & NIMA (never in mitosis gene a)-related kinase 6 & OTHER & 105.86 & NM_014397 \\
\hline NEK7 & & NIMA (never in mitosis gene a)-related kinase 7 & OTHER & 99.36 & NM_133494 \\
\hline
\end{tabular}


Table 2 (Continued)

\begin{tabular}{|c|c|c|c|c|c|}
\hline $\begin{array}{l}\text { Ambion } \\
\text { name }\end{array}$ & $\begin{array}{l}\text { Also } \\
\text { known as }\end{array}$ & Full name & $\begin{array}{l}\text { Kinase } \\
\text { subgroup }\end{array}$ & $\begin{array}{c}\text { ANL/ } \\
\text { neuron }\end{array}$ & RefSeq Ace \\
\hline PLK4 & STK18. SAK & polo-like kinase 4 (Drosophila) & OTHER & 100.84 & NM 014264 \\
\hline PRKWNK2 & Wnk2 & protein kinase, lysine deficient 2 & OTHER & 110.63 & NM_006648 \\
\hline PRKWNK3 & Wnk3 & protein kinase, lysine deficient 3 & OTHER & 106.31 & $\begin{array}{l}\text { NM_001002838, } \\
\text { NM_020922 }\end{array}$ \\
\hline PTK9L & A6r & PTK9L protein tyrosine kinase 9-like (A6-related protein) & OTHER & 117.06 & NM 007284 \\
\hline SCYL1 & NTKL & SCY1-like 1 (S. cerevisiae) & OTHER & 102.04 & NM_020680 \\
\hline$\overline{\text { STK35 }}$ & CLIK1 & serine/threonine kinase 35 & OTHER & 99.83 & NM_080836 \\
\hline TBK1 & & TANK-binding kinase 1 & OTHER & 118.72 & NM_013254 \\
\hline TLK1 & & tousled-like kinase 1 & OTHER & 108.42 & NM 012290 \\
\hline TOPK & PBK & PDZ binding kinase & OTHER & 101.71 & NM_018492 \\
\hline TP53RK & PRPK & TP53 regulating kinase & OTHER & 109.7 & NM_033550 \\
\hline ULK1 & & unc-51-like kinase 1 (C. elegans) & OTHER & 123.12 & NM_003565 \\
\hline ULK2 & & unc-51-like kinase 2 (C. elegans) & OTHER & 111.4 & NM 014683 \\
\hline$\overline{\mathrm{NPR} 1}$ & & $\begin{array}{l}\text { natriuretic peptide receptor } \mathrm{A} / \text { guanylate cyclase } \mathrm{A} \\
\text { (atrionatriuretic peptide receptor } \mathrm{A} \text { ) }\end{array}$ & $\mathrm{RGC}$ & 111.24 & NM_000906 \\
\hline MAP4K4 & NIK & mitogen-activated protein kinase kinase kinase kinase 4 & STE & 109.98 & $\begin{array}{l}\text { NM_004834. } \\
\text { NM_145686, } \\
\text { NM__145687 }^{-1458}\end{array}$ \\
\hline MY03B & & myosin IIIB & STE & 108.34 & NM_138995 \\
\hline TA01 & & Thousand-and one amino acid & STE & 108.31 & $\begin{array}{l}\text { NM } 004783 \\
\text { NM_016151 }\end{array}$ \\
\hline$\underline{\text { CERK }}$ & & ceramide kinase & & 115.91 & $\begin{array}{l}\text { NM_022766, } \\
\text { NM__182661 }^{-}\end{array}$ \\
\hline CKM & & creatine kinase, muscle & & 112.4 & NM_001824 \\
\hline CKMT2 & & creatine kinase, mitochondhal 2 (sarcomeric) & & 104.76 & NM 001825 \\
\hline DCK & & deoxycytidine kinase & & 101 & NM_000788 \\
\hline$\underline{\mathrm{DGKD}}$ & & diacylglycerol kinase, delta $130 \mathrm{kDa}$ & & 101.61 & $\begin{array}{l}\text { NM_003648, } \\
\text { NM_152879 }\end{array}$ \\
\hline DGUOK & & deoxyguanosine kinase & & 100.71 & $\begin{array}{l}\text { NM_001929, } \\
\text { NM_080915, } \\
\text { NM_080916, } \\
\text { NM_080917. } \\
\text { NM 080918 }\end{array}$ \\
\hline ETNK2 & & ethanolamine kinase 2 & & 102.67 & NM_018208 \\
\hline GALK1 & & galactokinase 1 & & 107.31 & NM_000154 \\
\hline NME3 & & non-metastatic cells 3 , protein expressed in & & 112.94 & NM_002513 \\
\hline PIP5K1A & & phosphatidylinositol-4-phosphate 5-kinase. type I, alpha & & 106.76 & NM 003557 \\
\hline P1P5K2A & & phosphatidylinositol-4-phosphate 5-kinase. type II, alpha & & 102.79 & NM_005028 \\
\hline PRKRA & & $\begin{array}{l}\text { protein kinase, interferon-inducible double stranded } \\
\text { RNA dependent activator }\end{array}$ & & 110.06 & NM_003690 \\
\hline TK1 & & thymidine kinase 1 , soluble & & 106.98 & NM_003258 \\
\hline TK2 & & thymidine kinase 2 , mitochondrial & & 105.58 & NM_004614 \\
\hline UCK1 & & uridine-cytidine kinase 1 & & 108.71 & NM_031432 \\
\hline
\end{tabular}

AGC, containing PKA, PKG, PKC families; ATYPICAL, 'atypical' kinases with no sequence similarity to typical kinases but are known or predicted to have enzymatic activity; CMGC, containing CDK, MAPK, GSK3, CLK families; OTHER, the Other group contains several kinase families that do not fit within any of the other main kinase groups; RGC, receptor guanylate cyclases; STE, homologues of yeast sterile 7, sterile 11, sterile 20 kinases. The table shows 66 protein kinases with RNAi phenotype of promoting neurite outgrowth in our assay condition. These candidates were grouped according to the subgroup classification in the KINOME (http://kinase.com/human/kinome/). ${ }^{43}$ ANL/neuron (average neurite length per neuron) represents average neurite length by three (underlined candidates) or two (un-underlined candidates) independent siRNAs calculated from two rounds of screens

compared to the anti-EGFP siRNA-treated controls $(100 \pm 8 \%)$.

To quantify regeneration in the sub-population of dopaminergic neurons in culture, we performed immunocytochemistry for tyrosine hydroxylase $(\mathrm{TH})$ and measured regeneration beyond the edge of the transection as in the total culture (Figure $5 \mathrm{~d}$ ). In general, regeneration of dopaminergic neurons was less pronounced compared to overall regeneration in culture, suggesting a lower regeneration potential of this sub-population (Figure 5c). Increased regeneration of $\mathrm{TH}$-positive neurons was observed with knockdown of DGUOK (131 $\pm 9 \%)$, MAP4K4 (124 $\pm 6 \%)$ and ULK1 $(130 \pm 8 \%)$ compared to the anti-EGFP siRNA-treated control.
Validation in Drosophila retinal degeneration. To address the physiological significance of our finding in vivo, we tested Drosophila orthologues of two candidate kinases essential for neurite retraction, ROCK1 and PKN1, for their ability to influence retinal degeneration in class III Autosomal Dominant Drosophila Retinitis Pigmentosa (ADRP). We used two mutant alleles of Drosophila ninaE gene, nina $E^{G 69 D}$ and nina $E^{R H 27}$, which share molecular and phenotypic characteristics identical to those found in human ADRP. ${ }^{27,28}$ Heterozygous ninaE flies exhibit agerelated retinal degeneration. ${ }^{28}$ The severity of degeneration intensified when the animals were reared in permanent light and to a lesser extent when reared in darkness ${ }^{29}$ (Figure 6a and b). We tested whether mutant alleles of the fly orthologue 
Table 3 RNAi knockdown inhibits LPA-induced neurite retraction

\begin{tabular}{|c|c|c|c|c|c|}
\hline $\begin{array}{l}\text { Ambion } \\
\text { name }\end{array}$ & $\begin{array}{l}\text { Also } \\
\text { known as }\end{array}$ & Full name & $\begin{array}{l}\text { Kinase } \\
\text { subgroup }\end{array}$ & $\begin{array}{c}\text { ANL/ } \\
\text { neurite }\end{array}$ & RefSeq Acc \\
\hline ADRBK1 & $\begin{array}{l}\text { BARK1/ } \\
\text { GRK2 }\end{array}$ & adrenergic, beta, receptor kinase 1 & AGC & 12.8 & NM_001619 \\
\hline AKT1 & & v-akt murine thymoma viral oncogene homolog 1 & AGC & 12.65 & NM 005163 \\
\hline GRK5 & GPRK5 & G protein-coupled receptor kinase 5 & AGC & 14.12 & NM_005308 \\
\hline LATS2 & & LATS, large tumor suppressor, homolog 2 (Drosophila) & $A G C$ & 13.41 & NM_014572 \\
\hline MAST2 & & microtubule associated serine/threonine kinase 2 & AGC & 14.6 & NM_015112 \\
\hline$\overline{\text { MASTL }}$ & & microtubule associated serine/threonine kinase-like & AGC & 13.25 & NM 032844 \\
\hline PDPK1 & PDK1 & 3-phosphoinositide dependent protein kinase-1 & AGC & 13.91 & $\begin{array}{l}\text { NM_002613, } \\
\text { NM_031268 }\end{array}$ \\
\hline PKN1 & PRK1 & protein kinase $\mathrm{N} 1$ & AGC & 13.3 & $\begin{array}{l}\text { NM_002741, } \\
\text { NM_213560 }\end{array}$ \\
\hline PRKCB1 & PKC beta & protein kinase $\mathrm{C}$, beta 1 & AGC & 14.68 & $\begin{array}{l}\text { NM } 002738, \\
\text { NM_212535 }\end{array}$ \\
\hline PRKCG & $\begin{array}{l}\text { PKC } \\
\text { gamma }\end{array}$ & protein kinase $\mathrm{C}$, gamma & AGC & 13.76 & NM_002739 \\
\hline PRKCl & PKC iota & protein kinase $\mathrm{C}$, iota & AGC & 14.89 & NM_002740 \\
\hline PRKY & & protein kinase, $Y$-linked & AGC & 15.12 & NM 002760 \\
\hline ROCK1 & & Rho-associated, coiled-coil containing protein kinase 1 & AGC & 14.18 & NM_005406 \\
\hline$\overline{\text { STK32B }}$ & YANK2 & serine/threonine kinase $32 \mathrm{~B}$ & AGC & 13.51 & NM_018401 \\
\hline STK38L & NDR2 & serine/threonine kinase 38 like & AGC & 13.43 & NM_015000 \\
\hline ADCK2 & CABC1 & aarF domain containing kinase 2 & ATYPICAL & 12.7 & NM 052853 \\
\hline$\overline{\mathrm{ADCK} 4}$ & CABC1 & aarF domain containing kinase 4 & ATYPICAL & 14.08 & NM_024876 \\
\hline CABC1 & ADCK3 & chaperone, ABC1 activity of bc1 complex like (S. pombe) & ATYPICAL & 12.62 & NM_020247 \\
\hline MIDORI & ALPK3 & & ATYPICAL & 13.73 & NM 020778 \\
\hline$\overline{\text { FASTK }}$ & & & ATYPICAL & 12.6 & $\begin{array}{l}\text { NM_006712, } \\
\text { NM_025096 }\end{array}$ \\
\hline HUNK & & hormonally upregulated Neu-associated kinase & CAMK & 12.98 & NM_014586 \\
\hline KIAA0999 & QSK & & CAMK & 13.71 & NM_025164 \\
\hline MKNK2 & MNK2 & MAP kinase interacting serine/threonine kinase 2 & CAMK & 14.83 & $\begin{array}{l}\text { NM } 017572, \\
\text { NM_199054 }\end{array}$ \\
\hline PHKG1 & & phosphorylase kinase, gamma 1 (muscle) & CAMK & 12.63 & NM_006213 \\
\hline PSKH2 & & protein serine kinase $\mathrm{H} 2$ & CAMK & 14.37 & NM_033126 \\
\hline STK22D & TSSK1 & serine/threonine kinase 22D (spermiogenesis associated) & CAMK & 13.7 & NM 032028 \\
\hline CDC2 & CDK1 & cell division cycle $2, \mathrm{G} 1$ to $\mathrm{S}$ and $\mathrm{G} 2$ to $\mathrm{M}$ & CMGC & 12.96 & $\begin{array}{l}\text { NM_001786, } \\
\text { NM_033379 }\end{array}$ \\
\hline HIPK1 & & homeodomain interacting protein kinase 1 & CMGC & 13.09 & $\begin{array}{l}\text { NM_152696, } \\
\text { NM_181358, } \\
\text { NM_198268, } \\
\text { NM_198269 }\end{array}$ \\
\hline SCYL1 & & SCY1-like 1 (S. cerevisiae) & OTHER & 13.1 & NM_020680 \\
\hline SGK & CLIK1 & serum/glucocorticoid regulated kinase & OTHER & 12.72 & NM_005627 \\
\hline TBK1 & & TANK-binding kinase 1 & OTHER & 12.48 & NM 013254 \\
\hline ULK1 & & unc-51-like kinase 1 (C. elegans) & OTHER & 14.41 & NM_003565 \\
\hline ULK2 & & unc-51-like kinase 2 (C. elegans) & OTHER & 12.61 & NM_014683 \\
\hline PTK9L & & PTK9L protein tyrosine kinase 9-like (A6-related protein) & OTHER & 12.93 & NM 007284 \\
\hline PAK6 & & p21(CDKN1A)-activated kinase 6 & STE & 12.03 & NM_020168 \\
\hline SLK & & STE20-like kinase (yeast) & STE & 13.54 & NM_014720 \\
\hline STK10 & LOK & serine/threonine kinase 10 & STE & 13.19 & NM_005990. \\
\hline MAP4K4 & HGK/NIK & mitogen-activated protein kinase kinase kinase kinase 4 & STE & 13.44 & $\begin{array}{l}\text { NM_004834, } \\
\text { NM_145686 } \\
\text { NM_145687 }\end{array}$ \\
\hline EGFR & & $\begin{array}{l}\text { epidermal growth factor receptor (erythroblastic leukemia viral } \\
\text { (v-erb-b) oncogene homolog. avian) }\end{array}$ & TK & 14.83 & $\begin{array}{l}\text { NM_005228, } \\
\text { NM_201282, } \\
\text { NM_201283, } \\
\text { NM_201284 }\end{array}$ \\
\hline FGFR1 & & $\begin{array}{l}\text { fibroblast growth factor receptor } 1 \text { (fms-related tyrosine kinase } 2 \text {, } \\
\text { Pfeiffer syndrome) }\end{array}$ & TK & 13.35 & $\begin{array}{l}\text { NM_000604. } \\
\text { NM_015850 } \\
\text { NM_023105, } \\
\text { NM_023106 }\end{array}$ \\
\hline FGFR4 & & fibroblast growth factor receptor 4 & TK & 14.48 & $\begin{array}{l}\text { NM_002011, } \\
\text { NM_022963 } \\
\text { NM_213647 }\end{array}$ \\
\hline FLT1 & VEGFR1 & $\begin{array}{l}\text { fms-related tyrosine kinase } 1 \text { (vascular endothelial growth factor/ } \\
\text { vascular permeability factor receptor) }\end{array}$ & TK & 13.4 & NM_002019 \\
\hline $\mathrm{HCK}$ & & hemopoietic cell kinase & TK & 12.77 & NM_002110 \\
\hline LTK & & leukocyte tyrosine kinase & TK & 13.51 & $\begin{array}{l}\text { NM 002344, } \\
\text { NM_206961 }\end{array}$ \\
\hline MST1R & RON & macrophage stimulating 1 receptor (c-met-related tyrosine kinase) & TK & 13.76 & NM_002447 \\
\hline NTRK1 & TRKA & neurotrophic tyrosine kinase, receptor, type 1 & TK & 13.75 & NM_002529 \\
\hline NTRK3 & TRKC & neurotrophic tyrosine kinase, receptor, type 3 & TK & 12.28 & NM_002530 \\
\hline PPGFRB & & platelet-derived growth factor receptor, beta polypeptide & TK & 12.22 & NM 002609 \\
\hline PTK2B & PYK2 & PTK2B protein tyrosine kinase 2 beta & TK & 13.01 & \\
\hline
\end{tabular}




\begin{tabular}{|c|c|c|c|c|c|}
\hline $\begin{array}{l}\text { Ambion } \\
\text { name }\end{array}$ & $\begin{array}{l}\text { Also } \\
\text { known as }\end{array}$ & Full name & $\begin{array}{l}\text { Kinase } \\
\text { subgroup }\end{array}$ & $\begin{array}{c}\text { ANL/ } \\
\text { neurite }\end{array}$ & RefSeq Acc \\
\hline & & & & & $\begin{array}{l}\text { NM_004103, } \\
\text { NM_173174, } \\
\text { NM_173175, } \\
\text { NM_173176 }\end{array}$ \\
\hline PTK6 & BRK & PTK6 protein tyrosine kinase 6 & TK & 13.54 & NM 005975 \\
\hline PTK7 & CCK4 & PTK7 protein tyrosine kinase 7 & TK & 13.83 & $\begin{array}{l}\text { NM_002821, } \\
\text { NM_152880 } \\
\text { NM_152881, } \\
\text { NM_152882 }\end{array}$ \\
\hline$\underline{\text { SRMS }}$ & SRM & $\begin{array}{l}\text { src-related kinase lacking } \mathrm{C} \text {-terminal regulatory tyrosine and } \\
\mathrm{N} \text {-terminal myristylation sites }\end{array}$ & TK & 13.39 & NM_080823. \\
\hline TEC & & tec protein tyrosine kinase & TK & 14.8 & NM_003215, \\
\hline TYR03 & SKY & TYR03 protein tyrosine kinase & TK & 13.43 & NM_006293 \\
\hline AMHR2 & MIAR2 & anti-Mullerian hormone receptor, type II & TKL & 13.57 & NM_020547 \\
\hline ILK & & integrin-linked kinase & TKL & 13.41 & NM 004517 \\
\hline IRAK3 & & interieukin-I receptor-associated kinase 3 & TKL & 12.61 & NM_007199 \\
\hline CERK & & ceramide kinase & & 14.1 & $\begin{array}{l}\text { NM_022766, } \\
\text { NM_182661 }\end{array}$ \\
\hline$\underline{\mathrm{DAB} 2}$ & & $\begin{array}{l}\text { disabled homolog 2, mitogen-responsive phosphoprotein } \\
\text { (Drosophila) }\end{array}$ & & 13.39 & NM_001343 \\
\hline$\underline{\mathrm{DGKD}}$ & & diacylglycerol kinase, delta I30 kDa & & 12.32 & $\begin{array}{l}\text { NM_003648, } \\
\text { NM_152879 }\end{array}$ \\
\hline DGKO & & diacylglycerol kinase, theta $110 \mathrm{kDa}$ & & 14.16 & NM_001347 \\
\hline FN3KRP & & fructosamine-3-kinase-related protein & & 12.36 & NM 024619 \\
\hline GK2 & & glycerol kinase 2 & & 12.26 & NM_033214 \\
\hline IHPK1 & & inositol hcxaphosphate kinase 1 & & 14.52 & NM_153273 \\
\hline NME3 & & non-metastatic cells 3 & & 12.66 & NM 002513 \\
\hline PGK2 & & phosphoglycerate kinase 2 & & 13.15 & NM_138733 \\
\hline PRPS2 & & phosphoribosyl pyrophosphate synthetase 2 & & 13.92 & NM_002765 \\
\hline TSKS & & testis-specific kinase substrate & & 13.11 & NM_021733 \\
\hline
\end{tabular}

AGC, containing PKA, PKG, PKC families; ATYPICAL, 'atypical' kinases with no sequence similarity to typical kinases but are known or predicted to have enzymatic activity; CAMK, calcium/calmodulin-dependent protein kinase; CMGC, containing CDK, MAPK, GSK3, CLK families; OTHER, the Other group contains several kinase families that do not fit within any of the other main kinase groups; STE, homologues of yeast sterile 7, sterile 11, sterile 20 kinases; TK, tyrosine kinase; TKL, tyrosine kinase-like. The table shows 79 protein kinases with RNAi phenotype of inhibiting LPA-induced neurite retraction in our assay condition. These candidates were grouped according to the subgroup classification in the KINOME (http://kinase.com/human/kinome/). ${ }^{43}$ ANL/neurite (average neurite length per neurite) represents average neurite length by three (underlined candidates) or two (un-underlined candidates) independent siRNAs calculated from two rounds of screens

of human ROCK1, rok, could influence light-induced retinal degeneration in ninaE flies. Heterozygous rok mutant suppressed retinal degeneration in ninaE heterozygous background (Figure 6a). We also tested another candidate kinase from the retraction screen, PKN1, using this lightinduced retinal degeneration assay. Similarly, heterozygous pkn mutant suppressed retinal degeneration in ninaE flies, although to a lesser extent than those exhibited by rok mutant (Figure 6b).

\section{Discussion}

A comprehensive understanding of the molecular modulators and signalling network involved in the processes of axon outgrowth, growth cone collapse, axon retraction and degeneration is fundamental in order to gain insight into the mechanism of neuronal degeneration and regeneration. Our genome-wide screen provides a comprehensive analysis and classification of kinase gene families on the basis of their role in neurite outgrowth and retraction. This study not only places known players of neurite outgrowth and retraction into a wider context, but also identifies a large group of kinases with previously unknown function or kinases not previously implicated in regulation of axonal growth/maintenance.
Our results show that approximately 8 and $9 \%$ of the whole KINOME is essential for the promotion and inhibition of neurite outgrowth, respectively. As expected, known kinase regulators of mammalian axonal outgrowth, such as TRKB, and members of the Eph receptor TK family and also kinase proteins essential for neuronal development in lower organisms, such as unc-51 and MINK, were revealed by the screen. ${ }^{30-33}$ Similarly, the identification of JAK1 and JAK2 kinases of the JAK/STAT pathway for neurite outgrowth (Table 1) is consistent with a previously described function of STAT3 activation, which is necessary to increase growth of dorsal root ganglion neurons and improve axonal regeneration in spinal cord after a conditioning injury. ${ }^{34}$

Nevertheless, the majority of the candidates, many of which have housekeeping functions such as mitochondrial DNA (mtDNA) synthesis and cell cycle-related kinases (Table 2), have not been described to influence neurite outgrowth. For example, in non-replicating cells such as neurons, where cytosolic deoxyribonucleotide triphosphate synthesis is downregulated, mtDNA synthesis depends solely on the mitochondrial salvage pathway enzymes, deoxyribonucleoside kinases. Intriguingly, RNAi downregulation of all four mammalian deoxyribonucleoside kinases, DCK, TK1, TK2 and DGUOK, promote neurite outgrowth. Mutations in DGUOK and TK2 have been found in patients 
with mtDNA depletion syndromes and $10-15 \%$ of these patients exhibit neuronal abnormalities. ${ }^{35}$ The identification of all deoxyribonucleoside kinases as negative regulators of neurite outgrowth suggests that mtDNA synthesis machinery negatively regulates neurite outgrowth and is essential for neuronal function.

a

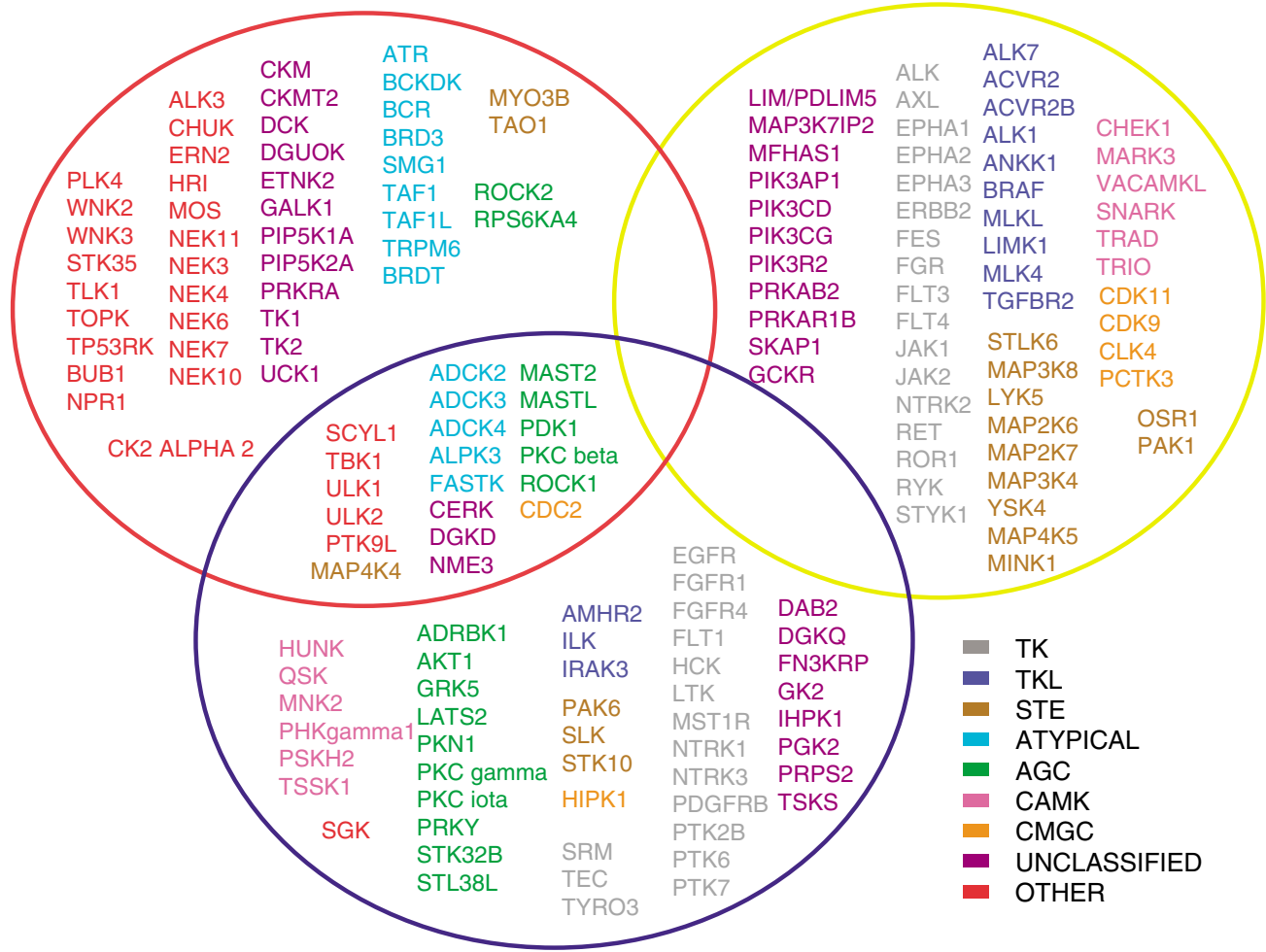

b

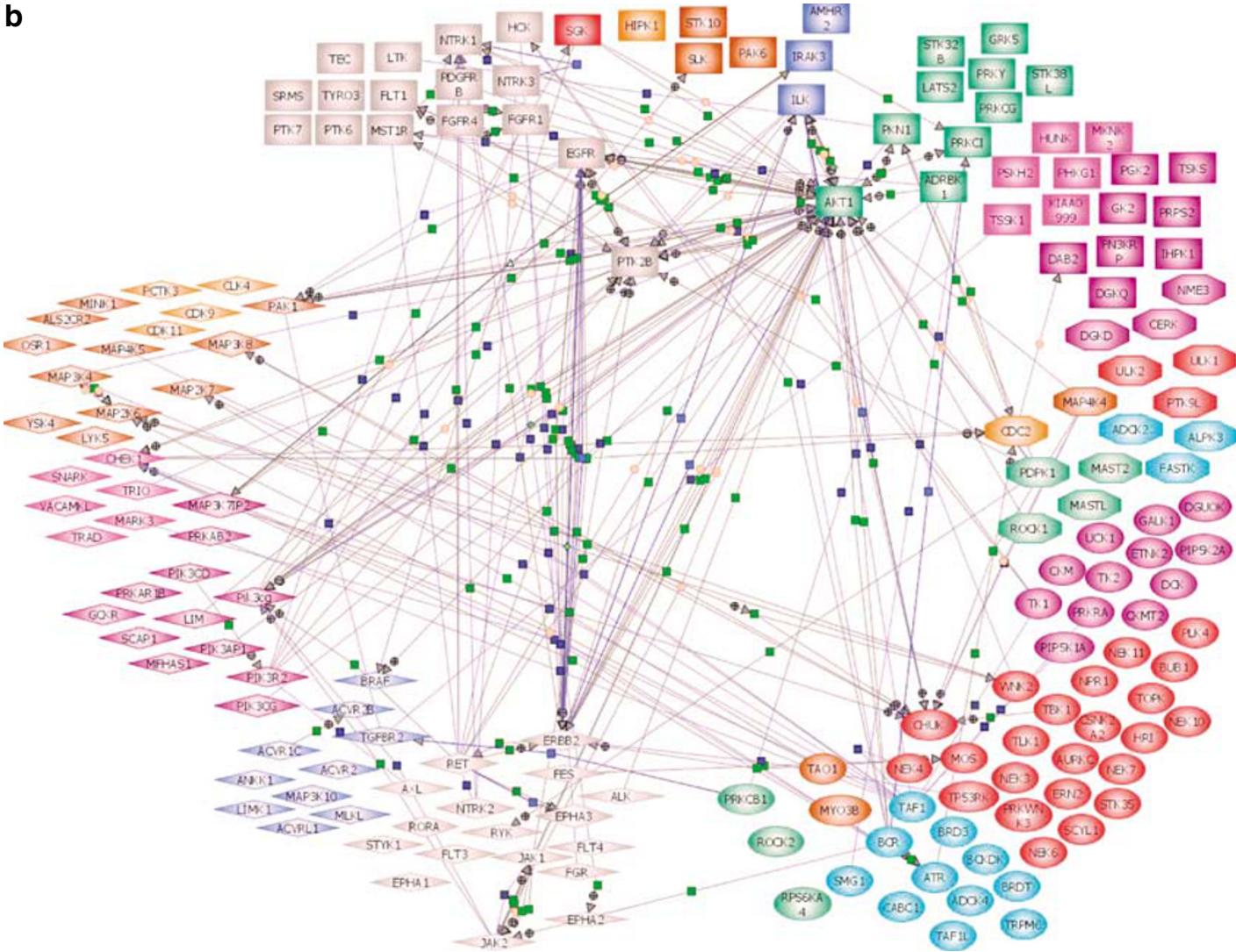



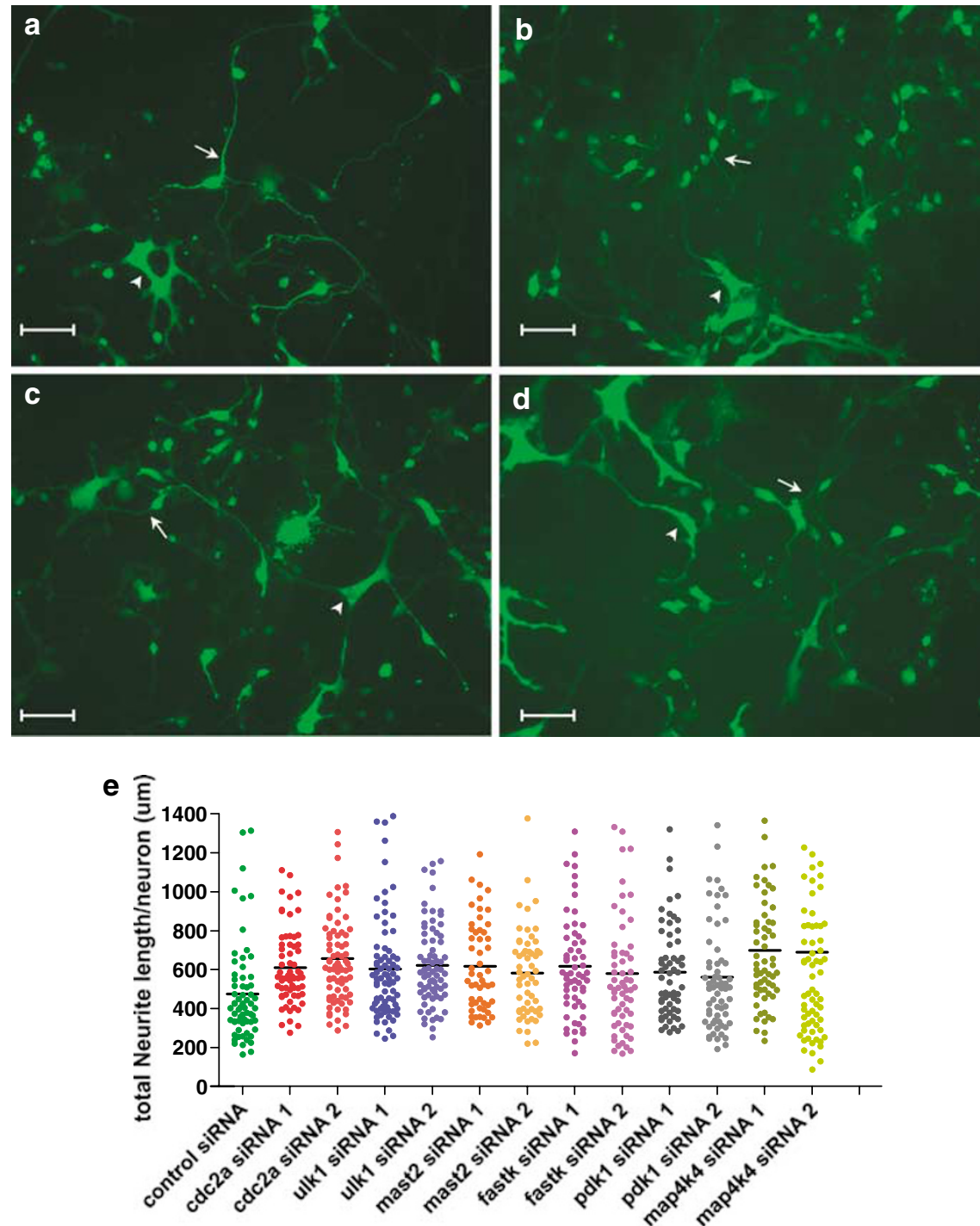

Figure 4 Neurite outgrowth of CGN cultures after siRNA-mediated knockdown. Representative fluorescent images of culture CGN co-transfected with pmaxGFP and scrambled siRNA (a) or siRNA-targeting MAST2 (b), ULK1 (c) and FASTK (d). Neurite length was traced on CGN population (arrows) but not on the distinctive larger population of glial cells (arrowhead). Scale bar $=50 \mu \mathrm{m}$. (e) A scatter plot of total neurite length per neuron for all sample traced. Each dot represents a traced neuron and the black bar represents the average neurite length per neuron $(\mu \mathrm{m})$ for each sample. siRNA-mediated knock down of selected kinases result in significantly longer total neurite length per neuron than the scramble siRNA, using the two-tailed $t$-test: $P=0.00039$ (cdc2a siRNA1), $P=0.000014$ (cdc2a siRNA2), $P=0.0018$ (ulk1 siRNA1), $P=0.00013$ (ulk1 siRNA2), $P=0.00089$ (mast2 siRNA1), $P=0.007$ (mast2 siRNA2), $P=0.0011$ (fastk siRNA1), $P=0.0258$ (fastk siRNA2), $P=0.0058$ (pdk1 siRNA1), $P=0.0348$ (pdk1 siRNA2), $P=0.000005$ (map4k4 siRNA1) and $P=0.00024$ (map4k4 siRNA2)

Figure 3 Candidate kinases identified in neurite outgrowth and retraction screens. All candidate kinases identified in both the neurite outgrowth and retraction screens are listed. (a) A Venn diagram showing RNAi downregulation of candidates in yellow or red circles resulted in inhibition or promotion of neurite outgrowth, respectively. RNAi downregulation of candidates in blue circles inhibits neurite retraction induced by LPA induction. Note that there are overlapping candidates between these data sets. All candidates were colour coded according to their subgroups classification in the KINOME (http://kinase.com/kinbase/). TK, tyrosine kinase in grey; TKL, tyrosine kinase-like in blue; STE, homologues of yeast sterile 7, sterile 11, sterile 20 kinases in brown; ATYPICAL, 'atypical' kinases with no sequence similarity to typical kinases but are known or predicted to have enzymatic activity in turquoise; AGC, containing PKA, PKG, PKC families in green; CAMK, calcium/calmodulin-dependent protein kinase in pink; CMGC, containing CDK, MAPK, GSK3, CLK families in orange; UNCLASSIFIED, candidates present in the library but could not be linked to a particular subgroup in the KINOME in purple; OTHER, the other group contains several kinase families that do not fit within any of the other main kinase groups in red. (b) The kinase signalling cross-talk, and connection between different members of kinases families identified in the screens. Links were established between identified kinases using PathwayArchitect ${ }^{\mathrm{TM}}$ software (Stratagene). For clarity, the pathway was generated automatically by a proprietary algorithm that finds direct connections between selected candidate kinases within the context of hand-curated and text-mined data present in the database. Candidates with rhombus or ellipse shapes are from the inhibition or promotion list of the outgrowth screen, respectively. Candidates with a rectangular shape are from the list of the inhibition of LPA-induced neurite retraction and those in octagon shape overlapped between promoting list and retraction list. Colour coding of kinases subgroup classification are as in (a). Small green squares linking two nodes represent positive or negative regulation as indicated. Small blue squares and orange circles represent binding interaction and protein modification between two nodes, respectively 
a

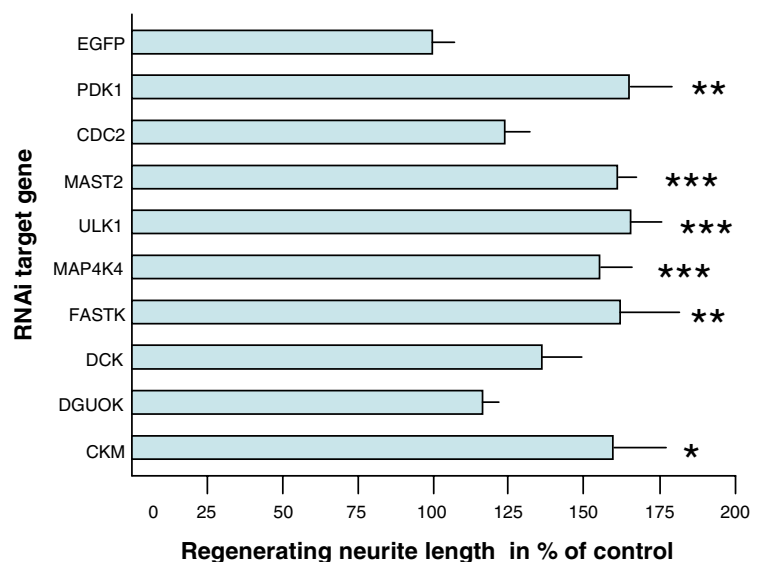

b

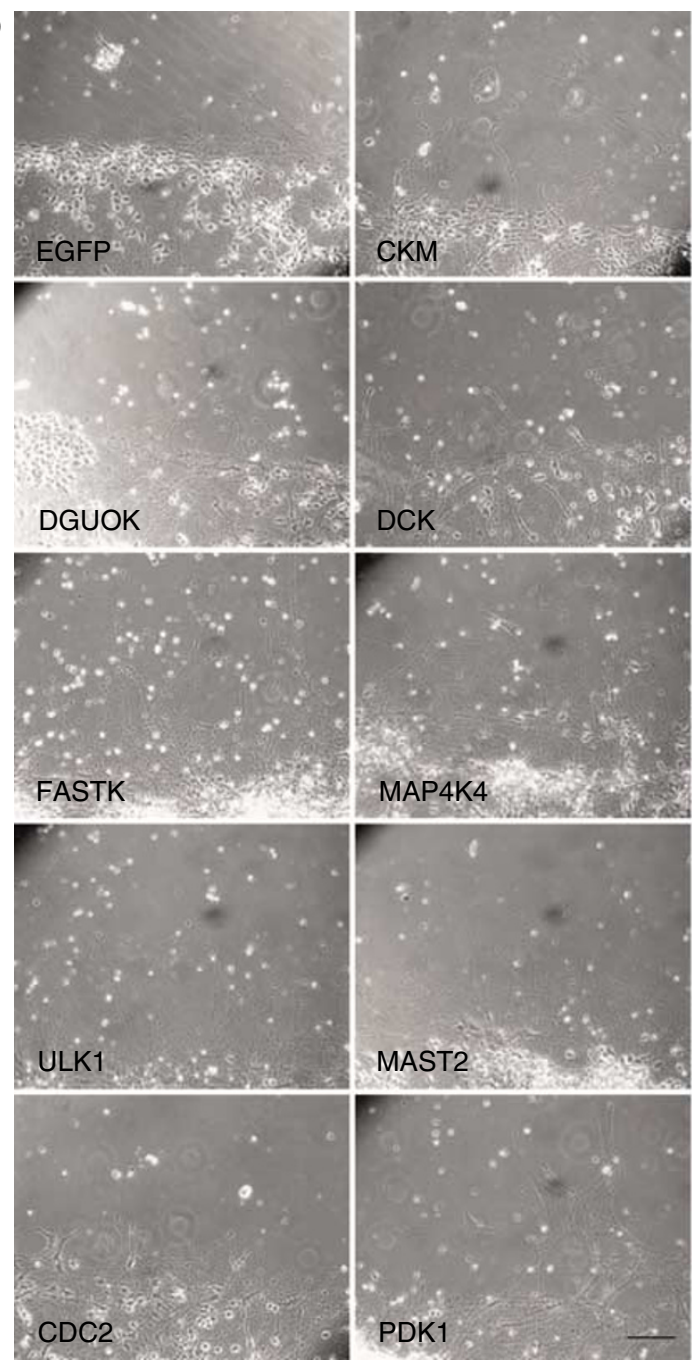

C
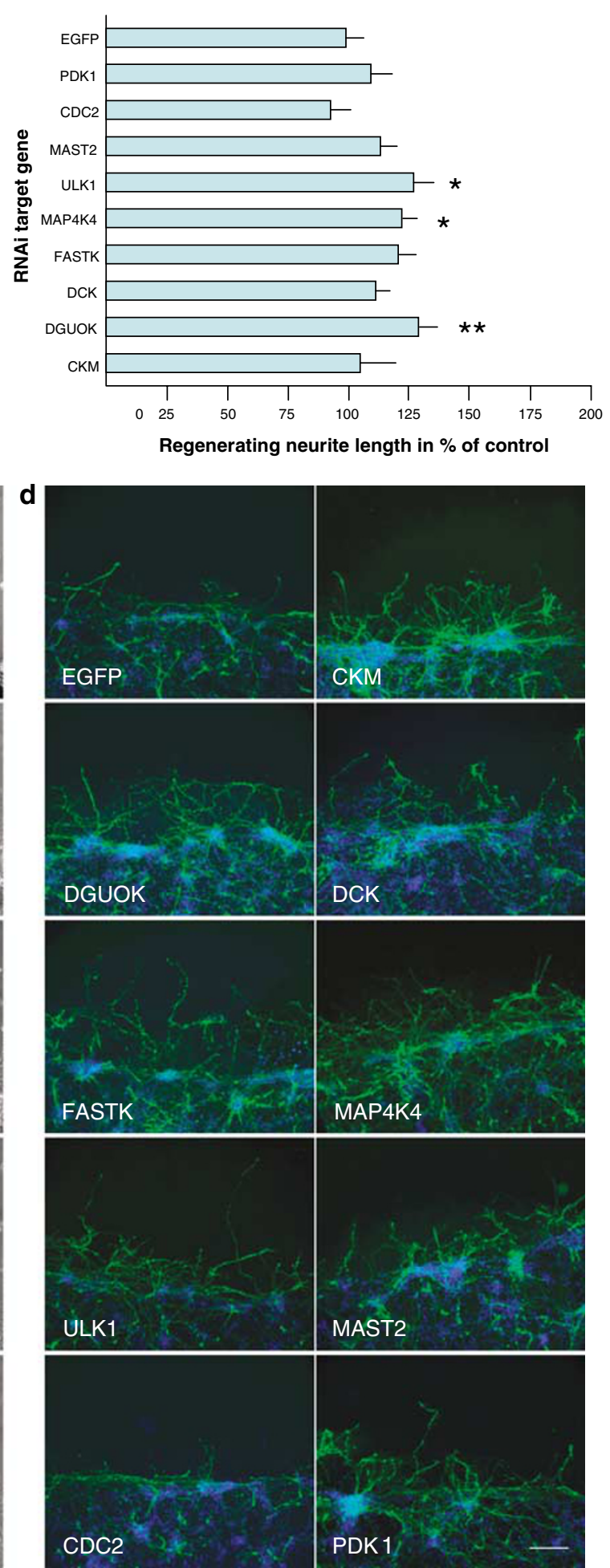

Figure 5 Regeneration of primary midbrain neurons after RNAi-induced knockdown. Bar diagrams represent quantification of neurite regeneration beyond the scratch lesion in the total knockdown culture given in percent compared to cultures treated with anti-EGFP siRNA; (a) regeneration in total culture, (c) regeneration in the dopaminergic sub-population. Data are given as mean \pm S.E.M. Neurite lengths were considered significantly different at ${ }^{*} P<0.05,{ }^{* *} P<0.01$ and ${ }^{* * *} P<0.001$ according to a two-sided $t$-test compared with the anti-EGFP siRNA-treated control. Photomicrographs: representative phase contrast (b) or epifluorescence images (d; blue - DAPI, green - TH) displaying regenerating neurites beyond the scratch lesion in cultures treated with siRNA against selected kinases or EGFP. Bar: $100 \mu \mathrm{m}$ 
a
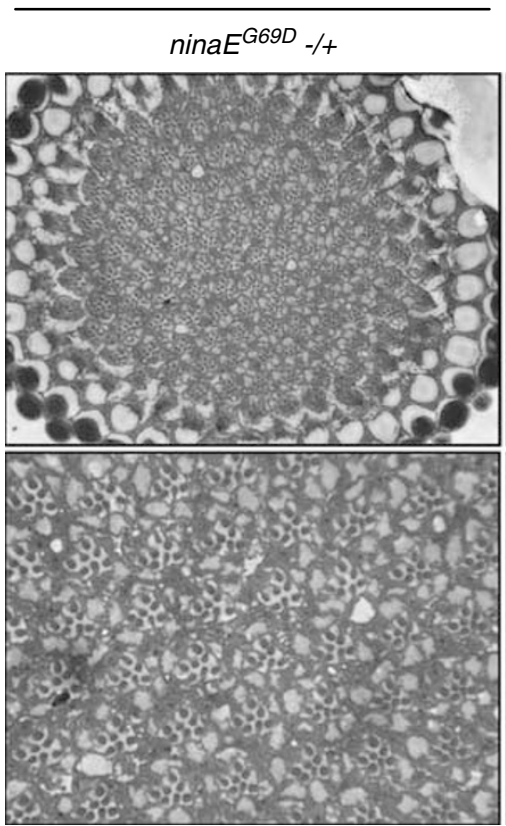

2000 lux light
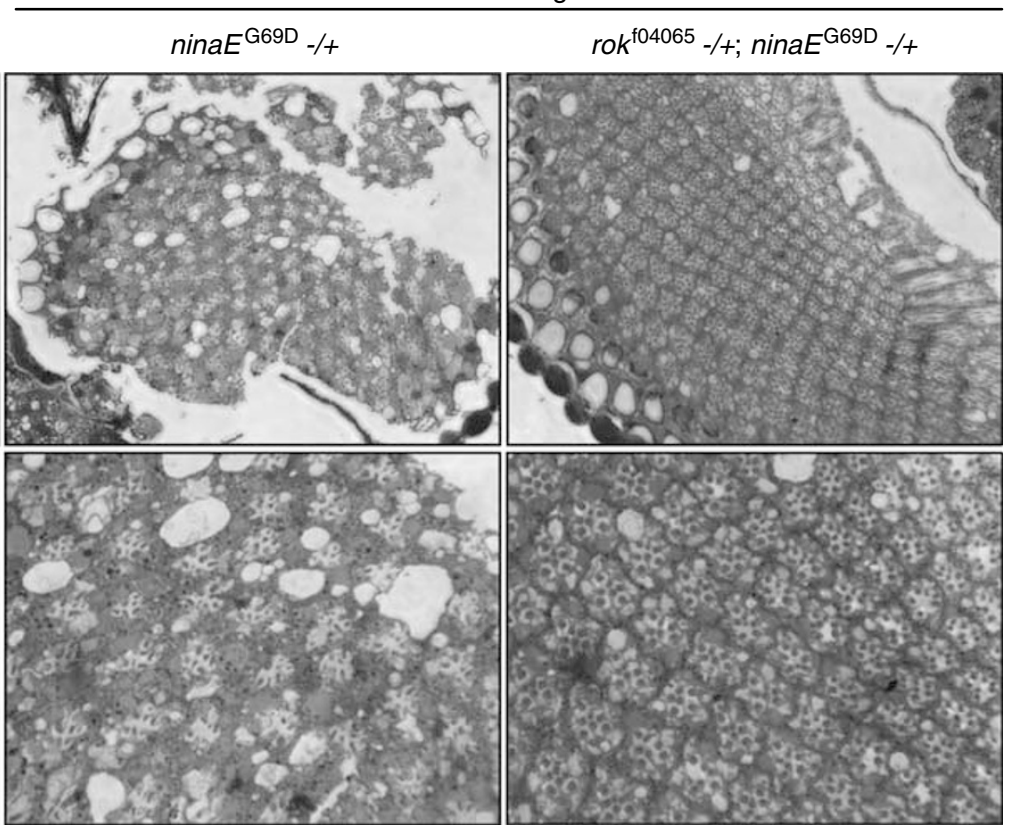

b

b $\quad \operatorname{ninaE^{RH27}-/+}$

$\operatorname{ninaE^{RH27}}-/+$ $p_{k n}^{r G 232}-/+;$ ninaE ${ }^{\mathrm{RH} 27}-/+$

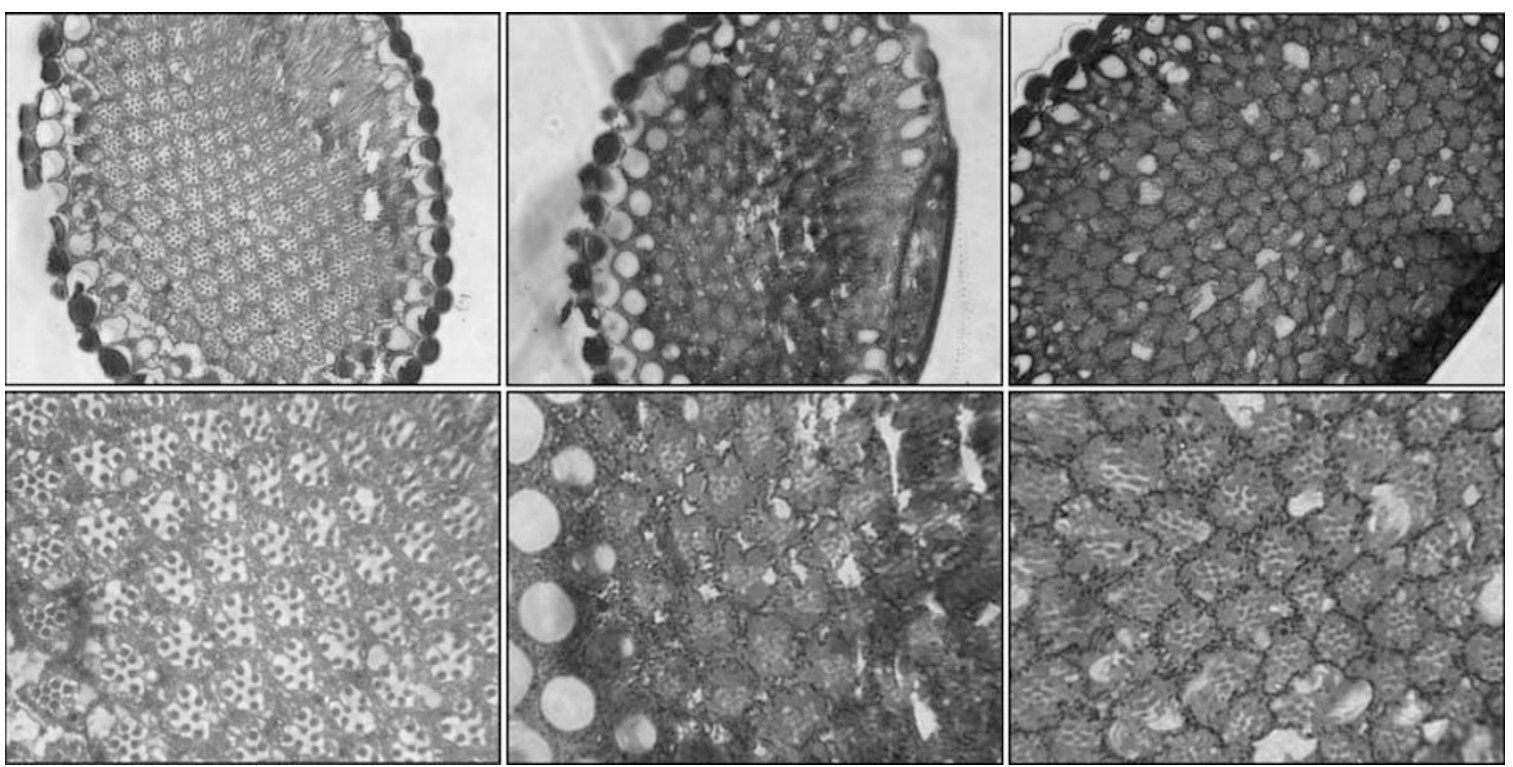

Figure 6 Haploinsufficiency of ROK and PKN1 suppressed ninaE- + retinal degeneration. Light micrographs of retinal tangential sections of flies: (a) nina ${ }^{\mathrm{G} 69 \mathrm{D}}-/+$, rok $^{\text {f04065 }}-/+$; nina $E^{G 69 D}-/+;$ (b) nina $E^{R H 27}-/+, p k n^{r G 232}-/+;$ nina $E^{R H 27}-/+$ raised in constant darkness or constant light (2000 lux) for 4 weeks. Light-induced retinal degeneration in two genetic backgrounds of ninaE mutations, nina $E^{G 69 D}$ and nina $E^{R H 27}$ were suppressed by haploinsufficiency of ROK (rok ${ }^{f 04065}$ ) and PKN (pkn ${ }^{r G 232}$ ). Upper panels of both $(\mathbf{a})$ and $(\mathbf{b})$ are $\times 40$ magnification, whereas the lower panels are of $\times 100$ magnification

Cell cycle exit represents the fundamental step to trigger differentiation of cells. It is therefore not surprising that downregulation of check point kinases, such as CHEK1, CDK11, CDK9 and CLK4, led to inhibition of neurite outgrowth (Table 1). These cannot be formally validated as direct modulators of axodendritic length, without testing their role in non-dividing cells. On the other hand, downregulation of a subset of cell cycle kinases, BUB1, AURKC, PLK4 and members of the NEK kinase family, promotes the outgrowth of neurites in our assay condition, suggesting that functions unrelated to cell cycle progression are modulated by these proteins. Indeed, recent convergence of data indicates a relationship between cilia, cell size and cell cycle progression. ${ }^{36}$ Based on our screen results, it is conceivable that signalling pathways regulating cytoskeletal rearrangement may be similar for both cell cycle progression and neurite outgrowth, and that the so-called cell cycle kinases may have a wider role. 
Finally, our outgrowth screen also identified CKM and CKMT2, two major isozymes of creatine kinase, as negative regulators of neurite outgrowth. The importance of these kinases as negative regulators of neurite outgrowth is further confirmed by the dopaminergic neuronal culture regeneration model (Figure 5). Supplementation of the substrate of this kinase, creatine, has been shown to protect neurons against neurotoxins in vitro and was able to slow down the progression of a number of neurodegenerative disease states in experimental animal models. ${ }^{37,38}$ Our finding further highlights the role of creatine kinase in neuroprotection and as a putative target for drugs aimed to promote neuronal regeneration and inhibit neuronal degeneration.

LPA-induced neurite retraction involves Rho GTPase signalling and ROCK1, which is a well-characterized mediator of neurite regression. ${ }^{25,39} \mathrm{ROCK}$ is crucial for mediating the growth inhibitory signal of myelin proteins in the CNS and its inhibition has been shown to increase axonal regeneration in vivo. ${ }^{40}$ In addition to ROCK1, a series of kinases previously unrelated to neurite degeneration was identified by the screen (Table 3). Among others, PI3K (via AKT and PKC) and cytoplasmic and receptor TK signalling (EGFR, FGFR, PDGFR and FLT1) were essential for LPA-induced neurite retraction. To validate both known and novel kinases revealed by the screen, we selected ROCK1 and a member of the PKC superfamily, PKN1. Haploinsufficiency of either rok, a Drosophila orthologue of human ROCK1, or PKN1 was able to suppress light-induced retinal degeneration in the fly model of ADRP.

Interestingly, 20 candidate kinases shared the property of negative modulators of neurite outgrowth as well as positive modulators of LPA-induced neurite retraction (Table 3 ). The integrity of the cytoskeleton is essential for the maintenance of axon stability, and axonal retraction requires intimate interaction between actin and microtubule cytoskeleton. ${ }^{41}$ It is likely that this subset of kinases is involved in the signalling pathways of the stabilization or destabilization of microtubules, actin or interactions between the two cytoskeletal systems.

The observation of subgroup clustering for all candidates in both screens suggests a different role for different kinase subgroups in neuronal development. For example, members of the AGC, OTHER and ATYPICAL subgroups were predominantly negative modulators of neurite outgrowth and retraction, whereas those of the TK, TKL and STE subgroups were predominantly positive modulators of neurite outgrowth (Figure 3). In addition, clustering of different kinase subgroups (Figure $3 \mathrm{~b}$ and Supplementary Figure 4) suggests that complex networks involving apparently unrelated groups of kinases are required for neuronal differentiation, degeneration and regeneration. The study of Figure $3 b$ and Supplementary Figure 4 also suggests that complex processes such as neurite length regulation are poorly described by classical, hierarchically arranged, vertical pathways.

This study is far from being an in-depth analysis of all kinases involved in the regulation of neurite length, but provides the first overall picture of the complex signalling network that involves different kinase families in neurite outgrowth and the opposite process of neurite retraction. It also identifies new putative cross-talks between previously unrelated signalling pathways. The mechanisms involved in degeneration of neuronal bodies and their processes, axons and dendrites, involve spatial and temporal signal segregation. ${ }^{4}$ The results of this screen are a template for further studies aimed to understand the molecular interaction leading to degeneration/outgrowth of neuronal processes and will help selection of appropriate targets for the design of new therapeutic strategies in neurodegenerative conditions. Protection of axonal and dendritic degeneration and stimulation of the regenerative capacity in damaged neurons might be the best option to improve clinical outcome in human neurodegenerative disorders.

\section{Materials and Methods}

siRNA library. A custom siRNA library targeting 750 human kinases with threefold redundancy was obtained from Ambion Inc. The three siRNA duplexes for each target were individually arrayed in a 96-well format (Supplementary Figure 1). Using Fam-labelled siRNA-targeting ROCKII, greater than $92 \%$ transfection efficiency was observed (Supplementary Figure 2) and, on average, greater than 66\% 'knockdown' for each mRNA target species was observed (Supplementary Figure 3).

High-throughput neurite outgrowth and retraction assays. $\mathrm{SH}$ SY5Y cells were seeded on 96-well plates, at density of 10000 cells per well, in nondifferentiating medium (DMEM with 10\% FCS plus $1 \% \mathrm{P} / \mathrm{S}$ ) and cultured overnight at $37^{\circ} \mathrm{C}$. $24 \mathrm{~h}$ post-seeding, non-differentiating medium was replaced with differentiating medium (Neurobasal medium (Invitrogen) supplemented with B27 supplement (Invitrogen), 1\%v/v Glutamine and $1 \mathrm{mM}$ db-cAMP (Sigma)) and the cells were transfected with $50 \mathrm{nM}$ siRNA using Lipofectamine 2000 reagent (Invitrogen). Forty-eight hours post-transfection, the cells were fixed with $3 \%$ paraformaldehyde in phosphate-buffered saline (PBS) for $20 \mathrm{~min}$ at room temperature (RT) followed by treatment for 5 min with $0.1 \%$ Triton-X-100 and $50 \%$ normal goat serum (NGS) in PBS for $1 \mathrm{~h}$ at RT. Neuronal-specific anti- $\beta$ III tubulin antibody (Promega) was used to stain the neurite processes at a dilution of 1 in 5000 in $50 \%$ NGS at RT for $3-4 \mathrm{~h}$ or $4^{\circ} \mathrm{C}$ overnight with low constant agitation. Bound antibody and nucleus were visualized using Alexa 546-conjugated secondary antibodies (Molecular Probe, 1 in 500) and Hoechst 33342 (Molecular Probe, 1 in 1000), respectively. Retraction assay was identical to the outgrowth assay as mentioned above, except for the addition of $10 \mu \mathrm{M}$ LPA (Sigma) for an hour before fixing the cells.

Automated images analysis. Cells were imaged using a Cellomics Kinetic Scan Reader high content microscope system and analysed using neurite outgrowth and extended neurite outgrowth BioApplications for the outgrowth and retraction assays, respectively. Twenty images per well per sample were taken at $\times 10$ magnification in a fully automated and blind manner. The total number of cell counts and the average neurite length per neuron and average neurite length per neurite for duplicated experiments were determined for neurite outgrowth and retraction assays, respectively.

CGNs culture and siRNA transfection. CGNs were prepared from 7-day-old Wistar rat pups and cultured in BME medium (Invitrogen) supplemented with $10 \% \mathrm{FCS}, 25 \mathrm{mM} \mathrm{KCl}, 1 \%$ Glutamax and $1 \% \mathrm{P} / \mathrm{S}$. Delivery of siRNA into CGNs was performed using the Amaxa nucleofection system (Amaxa GmbH). Optimization was performed with the Amaxa RNAi test kit using pmaxGFP ${ }^{T M}$ plasmid and siRNA directed against pmaxGFP. Following optimization, 6 million cells were co-nucleofected with pmaxGFP and either scrambled siRNA control or gene-specific siRNAs (Qiagen) at a final concentration of $50 \mathrm{nM}$. Nucleofected cells were plated on poly-L-lysine coated six-well plates and $48 \mathrm{~h}$ post-nucleofection cells were fixed with $3 \%$ paraformaldehyde. A minimum of 30 images of GFP-positive CGNs was acquired randomly from each well at $\times 20$ magnification using a Zeiss Axiovert 40 fluorescence microscope. The length of all neurite processes of at least 85 neurons per sample were traced using NeuronJ 1.01 imaging software (Erik Meijering) by two independent researchers. The total neurite length/neuron $(\mu \mathrm{m})$ was calculated and plotted as scatter plot for all samples traced. The data were analysed by using Student's $t$-test compared to scrambled siRNA control and differences were considered to be significant from $P<0.05$. 
In vitro regeneration assay and quantitative analysis of axonal regeneration. Primary midbrain cultures were prepared from embryonic rats on day 14 of gestation (E14) as previously described ${ }^{26}$ and maintained in DMEM-F12 (Invitrogen) supplemented with $2.5 \mathrm{mg} / \mathrm{ml} \mathrm{BSA} \mathrm{(35 \% ),} \mathrm{0.9 \%} \mathrm{D-} \mathrm{(} \mathrm{+} \mathrm{)-glucose} \mathrm{solution}$ (45\%), $2 \mathrm{mM}$ L-glutamine (PAA Laboratories, Pasching, Austria), $5 \mu \mathrm{g} / \mathrm{ml}$ insulin, 1:100 N1 medium supplement and 1: 100 PSN antibiotic mixture (Invitrogen). Half of the culture medium was exchanged at DIV 1 and subsequently every second day. Delivery of siRNA into CGNs was performed using the Amaxa nucleofection system (Amaxa GmbH). Two million cells were nucleoporated with a pool of two genespecific siRNAs (Qiagen) at a final concentration of $200 \mathrm{nM}$. Nucleoporated cells were plated on poly-L-ornithine/laminin-coated coverslips in 24-well plates at a density of $5 \times 10^{5}$ cells per well. On DIV 3 , a close neurital network was established in culture. A scratch was performed on the surface of the glass coverslip using a $2 \mathrm{~mm}$ thick rubber scraper resulting in a lesion on which axonal regeneration could be studied. Each coverslip was microscopically examined to ensure completeness of the scratch. To assess overall neurite outgrowth into the scratch, eight live images per condition were acquired at a random location along the scratch on DIV 6 using an inverted microscope (Axiovert $200 \mathrm{M}$; Carl Zeiss, Göttingen, Germany). To specifically quantify regeneration of dopaminergic neurons into the scratch, the culture was fixed with $4 \%$ paraformaldehyde for $10 \mathrm{~min}$ at RT followed by permeabilizing with $100 \%$ acetone for 10 min at $-20{ }^{\circ} \mathrm{C}$ and blocking with $10 \%$ NGS in PBS for 10 min at RT. Anti-TH antibody (Advanced ImmunoChemical, Long Beach, USA) was used to stain for TH at a dilution of $1: 250$ in 10\% NGS overnigh at $4{ }^{\circ} \mathrm{C}$. Bound antibody and nucleus were visualized using Cy2-conjugated goat anti-rabbit secondary antibody (Abcam, Cambridge, UK) and 4',6-diamidino-2 phenylindole (DAPI), respectively. Eight images per condition were captured. Quantification of the length of regenerating neurites was performed with the NeuronJ plug-in of the ImageJ software. In each image, the 10 longest processes were measured and averaged. For statistical analysis, all cell culture experiments were repeated at least twice.

Drosophila retinal degeneration assay. The following genotypes were used in this study: nina $E^{G 69 D}$ and nina $E^{R H 27}$ were used as models for the class III ADRP, ${ }^{27-28} P K N^{r G 232} / C y o, \quad P K N^{k 11209} / C y o, \quad r o k[1] / F M 7 i, \quad r o k[2] / F M 7 i$ and $\operatorname{rok}[$ f04065]/FM7i were from Bloomington stock center. Fly stocks were maintained on standard cornmeal agar media at $25^{\circ} \mathrm{C}$ in $12 \mathrm{~h}$ daylight and $12 \mathrm{~h}$ darkness. For light-induced retinal degeneration assay, 20-30 flies with the relevant genotypes were selected and cultured in glass vials at $25^{\circ} \mathrm{C}$ in permanent light (around 2000 lux) or darkness for 4 weeks. The vials were changed frequently to avoid mixing of the flies with eventual progeny. Tangential plastic sections were performed as previously described, ${ }^{42}$ and toluidine blue was used as a dye to increase the contrast.

Acknowledgements. We thank Veronique Planchamp and Anja Krauss for assistance in dopaminergic regeneration assay, Roger Snowdon for assistance in FACS analysis and high throughput screening, Maria Guerra Martin for preparation of CGN cultures, Pedro Domingos (HHMl, The Rockefeller University) and Bloomington Stock Center for fly strains, the Kyriacou lab members for technical assistance in fly work, David Dinsdale, Judy McWilliams and Tim Smith for assistance with TEM, Paul Glynn for critical paper review and Shu Dong Zhang for assistance with statistical analysis.

1. Yuan J, Lipinski M, Degterev A. Diversity in the mechanisms of neuronal cell death. Neuron 2003; 40: 401-413

2. Finn JT, Weil M, Archer F, Siman R, Srinivasan A, Raff MC. Evidence that Wallerian degeneration and localized axon degeneration induced by local neurotrophin deprivation do not involve caspases. J Neurosci 2000; 20: 1333-1341.

3. Raff MC, Whitmore AV, Finn JT. Axonal self-destruction and neurodegeneration. Science 2002; 296: 868-871.

4. Berliocchi L, Fava E, Leist M, Horvat V, Dinsdale D, Read D et al. Botulinum neurotoxin C initiates two different programs for neurite degeneration and neuronal apoptosis. J Cell Biol 2005; 168: 607-618

5. Dent EW, Gertler FB. Cytoskeletal dynamics and transport in growth cone motility and axon guidance. Neuron 2003; 40: 209-227.

6. Yoshimura T, Arimura N, Kaibuchi K. Signaling networks in neuronal polarization. J Neurosci 2006; 26: 10626-10630.

7. Dancey J, Sausville EA. Issues and progress with protein kinase inhibitors for cance treatment. Nat Rev Drug Discov 2003; 2: 296-313.
8. Melnikova I, Golden J. Targeting protein kinases. Nat Rev Drug Discov 2004; 3: 993-994.

9. Smith PD, O'Hare MJ, Park DS. Emerging pathogenic role for cyclin dependent kinases in neurodegeneration. Cell Cycle 2004; 3: 289-291.

10. Angelo M, Plattner F, Giese KP. Cyclin-dependent kinase 5 in synaptic plasticity, learning and memory. J Neurochem 2006; 99: 353-370.

11. Lucas JJ, Hernandez F, Gomez-Ramos P, Moran MA, Hen R, Avila J. Decreased nuclear beta-catenin, tau hyperphosphorylation and neurodegeneration in GSK-3beta conditional transgenic mice. EMBO J 2001; 20: 27-39.

12. Hatano Y, Li Y, Sato K, Asakawa S, Yamamura Y, Tomiyama $\mathrm{H}$ et al. Novel PINK1 mutations in early-onset parkinsonism. Ann Neurol 2004; 56: 424-427.

13. Valente EM, Abou-Sleiman PM, Caputo V, Muqit MM, Harvey K, Gispert S et al. Hereditary early-onset Parkinson's disease caused by mutations in PINK1. Science 2004; 304 : 1158-1160.

14. Klein C, Schlossmacher MG. The genetics of Parkinson disease: implications for neurological care. Nat Clin Pract Neurol 2006; 2: 136-146.

15. Paisan-Ruiz C, Jain S, Evans EW, Gilks WP, Simon J, van der Brug M et al. Cloning of the gene containing mutations that cause PARK8-linked Parkinson's disease. Neuron 2004; 44: $595-600$.

16. Zimprich $A$, Biskup $S$, Leitner $P$, Lichtner $P$, Farrer $M$, Lincoln $S$ et al. Mutations in LRRK2 cause autosomal-dominant parkinsonism with pleomorphic pathology. Neuron 2004; 44: 601-607.

17. Park J, Lee SB, Lee S, Kim Y, Song S, Kim S et al. Mitochondrial dysfunction in Drosophila PINK1 mutants is complemented by parkin. Nature 2006; 441: 1157-1161.

18. Petit A, Kawarai T, Paitel E, Sanjo N, Maj M, Scheid M et al. Wild-type PINK1 prevents basal and induced neuronal apoptosis, a protective effect abrogated by Parkinson diseaserelated mutations. J Biol Chem 2005; 280: 34025-34032.

19. Gloeckner CJ, Kinkl N, Schumacher A, Braun RJ, O'Neill E, Meitinger T et al. The Parkinson disease causing LRRK2 mutation I2020T is associated with increased kinase activity. Hum Mol Genet 2006; 15: 223-232.

20. West AB, Moore DJ, Biskup S, Bugayenko A, Smith WW, Ross CA et al. Parkinson's disease-associated mutations in leucine-rich repeat kinase 2 augment kinase activity. Proc Natl Acad Sci USA 2005; 102: 16842-16847.

21. Smith WW, Pei Z, Jiang $H$, Moore DJ, Liang $Y$, West $A B$ et al. Leucine-rich repeat kinase 2 (LRRK2) interacts with parkin, and mutant LRRK2 induces neuronal degeneration. Proc Natl Acad Sci USA 2005; 102: 18676-18681.

22. Smith WW, Pei Z, Jiang H, Dawson VL, Dawson TM, Ross CA. Kinase activity of mutant LRRK2 mediates neuronal toxicity. Nat Neurosci 2006; 9: 1231-1233.

23. Branchi I, Bichler Z, Minghetti L, Delabar JM, Malchiodi-Albedi F, Gonzalez MC et al. Transgenic mouse in vivo library of human Down syndrome critical region 1: association between DYRK1A overexpression, brain development abnormalities, and cell cycle protein alteration. J Neuropathol Exp Neurol 2004; 63: 429-440.

24. Lee G, Tanaka M, Park K, Lee SS, Kim YM, Junn E et al. Casein kinase II-mediated phosphorylation regulates alpha-synuclein/synphilin-1 interaction and inclusion body formation. J Biol Chem 2004; 279: 6834-6839.

25. Katoh H, Aoki J, Ichikawa A, Negishi M. p160 RhoA-binding kinase ROKalpha induces neurite retraction. J Biol Chem 1998; 273: 2489-2492.

26. Lingor $\mathrm{P}$, Unsicker K, Krieglstein K. GDNF and NT-4 protect midbrain dopaminergic neurons from toxic damage by iron and nitric oxide. Exp Neurol 2000; 163: 55-62.

27. Colley NJ, Cassill JA, Baker EK, Zuker CS. Defective intracellular transport is the molecular basis of rhodopsin-dependent dominant retinal degeneration. Proc Natl Acad Sci USA 1995; 92: 3070-3074.

28. Kurada P, O'Tousa JE. Retinal degeneration caused by dominant rhodopsin mutations in Drosophila. Neuron 1995; 14: 571-579.

29. Davidson FF, Steller H. Blocking apoptosis prevents blindness in Drosophila retinal degeneration mutants. Nature 1998; 391: 587-591.

30. Poinat $P$, De Arcangelis A, Sookhareea S, Zhu X, Hedgecock EM, Labouesse M et al. A conserved interaction between beta1 integrin/PAT-3 and Nck-interacting kinase/ MIG-15 that mediates commissural axon navigation in $C$ elegans. Curr Biol 2002; 12: 622-631.

31. Tomoda T, Kim JH, Zhan C, Hatten ME. Role of Unc51.1 and its binding partners in CNS axon outgrowth. Genes Dev 2004; 18: 541-558.

32. Minichiello L, Casagranda F, Tatche RS, Stucky CL, Postigo A, Lewin GR et al. Point mutation in trkB causes loss of NT4-dependent neurons without major effects on diverse BDNF responses. Neuron 1998; 21: 335-345.

33. Murai KK, Pasquale EB. New exchanges in eph-dependent growth cone dynamics. Neuron 2005; 46: 161-163.

34. Qiu J, Cafferty WB, McMahon SB, Thompson SW. Conditioning injury-induced spinal axon regeneration requires signal transducer and activator of transcription 3 activation. J Neurosci 2005; 25: 1645-1653.

35. Spinazzola A, Zeviani M. Disorders of nuclear-mitochondrial intergenomic signaling. Gene 2005; 354: 162-168.

36. Quarmby LM, Parker JD. Cilia and the cell cycle? J Cell Biol 2005; 169: 707-710.

37. Ferrante RJ, Andreassen OA, Jenkins BG, Dedeoglu A, Kuemmerle S, Kubilus JK et al. Neuroprotective effects of creatine in a transgenic mouse model of Huntington's disease. J Neurosci 2000; 20: 4389-4397. 
38. Brewer GJ, Wallimann TW. Protective effect of the energy precursor creatine against toxicity of glutamate and beta-amyloid in rat hippocampal neurons. J Neurochem 2000; 74 : 1968-1978.

39. Fukushima N. LPA in neural cell development. J Cell Biochem 2004; 92: 993-1003.

40. Lingor P, Teusch N, Schwarz K, Mueller R, Mack H, Bahr M et al. Inhibition of Rho kinase (ROCK) increases neurite outgrowth on chondroitin sulphate proteoglycan in vitro and axonal regeneration in the adult optic nerve in vivo. J Neurochem 2007; 103: 181-189.
41. Ahmad FJ, Hughey J, Wittmann T, Hyman A, Greaser M, Baas PW. Motor proteins regulate force interactions between microtubules and microfilaments in the axon. Nat Cell Biol 2000; 2: 276-280.

42. Tomlinson A. The cellular dynamics of pattern formation in the eye of Drosophila. J Embryol Exp Morphol 1985; 89: 313-331.

43. Manning G, Whyte DB, Martinez R, Hunter T, Sudarsanam S. The protein kinase complement of the human genome. Science 2002; 298: 1912-1934.

Supplementary Information accompanies the paper on Cell Death and Differentiation website (http://www.nature.com/cdd) 